\title{
Life-Cycle Assessment of Two Potable Water Reuse Technologies: MF/RO/UV-AOP Treatment and Hybrid Osmotic Membrane Bioreactors
}

Ryan W. Holloway ${ }^{1}$, Leslie Miller-Robbie ${ }^{1}$, Mehul Patel $^{2}$, Jennifer R. Stokes ${ }^{3}$, Junko MunakataMarr ${ }^{1}$, Jason Dadakis ${ }^{2}$, and Tzahi Y. Cath ${ }^{1 *}$

${ }^{1}$ Colorado School of Mines, Golden, Colorado, USA

${ }^{2}$ Orange County Water District, Fountain Valley, California, USA

${ }^{3}$ University of California, Berkeley, California, USA

* Corresponding author: e-mail: tcath@mines.edu; phone: (303) 273-3402; fax: (303) 273-3413

A manuscript prepared for possible publication in

Journal of Membrane Science

October 2015 


\begin{abstract}
A life cycle assessment tool and methodology were used to study two potable reuse treatment schemes: a full advanced treatment (FAT) approach and a hybrid ultrafiltration osmotic membrane bioreactor (UFO-MBR). FAT combines conventional wastewater treatment followed by low-pressure membrane filtration, reverse osmosis (RO), and ultraviolet advanced oxidation processes (UV-AOP). The UFO-MBR couples biological treatment processes with forward osmosis (FO) membranes and ultrafiltration (UF) membranes in one integrated system. RO is coupled with FO in the UFO-MBR process to produce ultra-pure water and a reconcentrated draw solution (DS) for reuse in the FO process. Construction material, energy demand, and chemical use data were collected and calculated to determine the energy use and a subset of environmental impacts of each system. Results from the LCA illustrate that the energy use and environmental impacts of FAT are lower than those of UFO-MBR treatment. The higher impacts of UFO-MBR treatment were associated with the required large area of the FO membrane and high RO energy use. UFO-MBR treatment was further assessed using higher permeability FO membranes and RO energy recovery. Following simulation of process optimization, the environmental impacts of UFO-MBR were brought much closer to those of FAT.
\end{abstract}

Keywords: Life cycle assessment; water reuse; potable reuse; forward osmosis; reverse osmosis; osmotic membrane bioreactor 


\section{Introduction}

Water reuse is being practiced in many water-scarce regions to complement fresh water supplies through non-potable, indirect potable, and direct potable water reuse [1]. Conventional wastewater treatment processes are acceptable for non-potable water reuse applications (e.g., turf grass, landscape, and agricultural irrigation) that do not require the wastewater to be treated to drinking water standards. However, indirect potable reuse (e.g., surface water and groundwater augmentation) and direct potable reuse schemes require an advanced multi-barrier treatment (i.e., biological, chemical, and physical processes) to protect the public from pathogens, trace organic chemicals (TOrCs), and other contaminants of concern [1]. Although potable reuse requires additional treatment compared to other reuse options, it is an attractive option for several reasons: 1) treated water is not contaminated by inorganic and organic pollutants contained in the natural aquatic environment, thereby not requiring a second round of treatment as with indirect reuse, 2) existing drinking water infrastructure can be used, 3) reuse water can potentially offset peak energy and water demands in existing drinking water treatment facilities (i.e., avoid operation at maximum capacity on peak demand days when the environmental impacts of supplying water are highest), and 4) improve supply resiliency with local, drought-independent water. The benefits of potable reuse and the challenges of treating wastewater to meet drinking water standards have prompted research, development, and application of advanced treatment technologies [2].

\subsection{Life cycle assessment of reuse technologies}

Water managers and decision makers in water-scarce regions have several options for new water supplies. These include importing water, seawater desalination, brackish water desalination, and water reuse [2-5]. The best water supply choice is not always clear and decisions can be further complicated by the multitude of available technologies that can produce waters of similar quality [6]. Life cycle assessment (LCA) can help clarify which combinations of water sources and processes are the best choice. LCA is a common method to holistically measure the environmental impacts (e.g., greenhouse gas (GHG) emissions and energy demand) of a system and system alternatives. LCA is a 'cradle to grave' approach that evaluates the effects of materials acquisition and manufacturing, construction, and system operation [7, 8]. 
Previous LCA studies assessing water supply options have determined that under certain conditions life cycle impacts of water reuse on the environment are similar to those for imported water (transfer of water between geographical regions) and have a much lower environmental impact than seawater desalination [3-5]. Although water reuse has been shown to have equal or lower environmental impact than other water supply options, very few LCA studies have been published on the life-cycle impact of different water reuse technologies [6, 9-12]. In one such study, Ortiz et al. [6] found that submerged membrane bioreactor (MBR) configurations had lower life-cycle impacts compared to traditional tertiary wastewater treatment coupled with external membrane filtration. This finding from Ortiz et al. is somewhat surprising considering that MBRs are often cited as using more energy compared to traditional tertiary treatment followed by membrane filtration [13]. This point illustrates that the holistic methodology used in LCA studies provides a different insight into system selection compared to traditional system analyses that only include cost and energy data. In this study, two potable reuse technologies, the established potable reuse scheme and a new hybrid osmotic MBR, are evaluated using an LCA methodology to assess the environmental impacts of construction, maintenance, and operation of these two distinct water reuse schemes.

\subsection{Established potable reuse scheme}

A common treatment train considered for potable water reuse is conventional tertiary wastewater treatment followed by low-pressure membrane filtration (microfiltration (MF) or ultrafiltration (UF)), high-pressure reverse osmosis (RO) separation, and ultraviolet light advanced oxidation processes (UV-AOP). For the purposes of this study, this configuration will be referred to as full advanced treatment (FAT) train. Conventional tertiary treatment is used to remove carbon, nitrogen, and phosphorus from wastewater using biologically active aerobic and anoxic reactors. Low-pressure MF and UF membranes remove nanometer-size particles and larger (including microorganisms) from wastewater, providing superior and consistent water quality compared to traditional media filtration [14]. Dissolved organic matter (such as TOrCs) and inorganics (such as sodium, chloride, sulfate, phosphate, calcium, and magnesium) that pass through the low-pressure membranes are almost completely separated from water by the highly selective, semipermeable RO membranes [6, 15-17]. Finally, UV-AOP combines oxidation and UV treatment to degrade any remaining low-molecular weight organic compounds through 
photolysis and chemical oxidation reactions [18, 19]. Although very successful for treating wastewater to drinking water quality, the large physical footprint, increased capital cost, need for RO concentrate disposal, and high energy consumption make it necessary to explore other technologies and schemes for potable reuse of impaired water.

\subsection{Osmotic membrane bioreactor}

Implementing a MF or UF MBR into the FAT potable reuse scheme alleviates potential physical space limitations and improves the biological treatment processes, but does not mitigate concerns associated with TOrC and nutrient removal, capital cost, RO concentrate disposal, and high energy consumption. In an attempt to address these problems, researchers have investigated osmotic membrane bioreactors (OMBRs) as a potential improvement to FAT [20-32]. In the OMBR, water is drawn across a selective semi-permeable forward osmosis (FO) membrane from a low-salinity activated sludge to a high-salinity draw solution (DS) driven by the difference in osmotic pressure between the two streams. In most instances an RO system is utilized to reconcentrate the DS after it becomes diluted during the FO process, and to produce high purity product water. The potential benefits of using an OMBR coupled with an RO subsystem compared to the FAT reuse scheme include: 1) the FO membrane provides a superior barrier to TOrCs [21, 23, 33-38], 2) the FO membrane protects the RO membrane from fouling and reduces RO membrane cleaning requirements [39], and 3) RO brine disposal is substantially reduced when the system is operated in a closed-loop configuration.

Initial OMBR bench-scale investigations highlighted the potential advantages of using FO membranes in activated sludge, including minimal membrane fouling, sustainable nutrient removal, and excellent rejection of nutrients and TOrCs [20-22]. Although low membrane fouling was observed, water flux declined in each of the early bench-scale investigations due to salts accumulating in the OMBR bioreactors. Salts slowly accumulate in the OMBR bioreactors due to diffusion of solutes across the FO membrane from the concentrated DS to the activated sludge and due to the retention of salts contained in the influent by the FO membranes. Elevated salt concentrations in the bioreactors have also been shown to inhibit the microbial activity in the activated sludge [21, 24, 26, 27].

\subsection{Hybrid ultrafiltration osmotic membrane bioreactor}


To alleviate problems associated with high bioreactor salinities that occur in continuously operating OMBRs, low-pressure UF membrane filtration can be coupled with an OMBR in a hybrid configuration referred to as an ultrafiltration osmotic membrane bioreactor (UFO-MBR) $[23,24]$. Long-term evaluations of the UFO-MBR revealed that the bioreactor salinity could be maintained at relatively low concentrations ( $<1.5 \mathrm{~g} / \mathrm{L}$-total dissolved solids (TDS)), thereby maintaining the driving force (salinity difference between the bioreactor and DS) for water flux across the FO membrane and limiting any inhibition of the microbial community responsible for carbon oxidation, nitrification/denitrification, and phosphorous removal.

In addition to reducing bioreactor salinity, the hybrid UFO-MBR system will produce two different reuse streams: non-potable water (through the UF membrane) and potable water (through the FO and RO membranes). The UF permeate stream is rich in nitrogen and phosphorus that accumulate in the bioreactors due to the high rejection of these nutrients by the FO membrane. Nutrients can be recovered from the UF permeate as fertilizers or other beneficial products, while the water can be utilized for landscape irrigation. Though nutrient-rich water may also be beneficial for use in agriculture, this study focused on urban applications. The water drawn from the activated sludge across the FO membrane into the concentrated DS is recovered using a reconcentration process such as RO or membrane distillation (MD) [23, 24, 40, 41]. Coupling two tight membrane barriers (FO in the OMBR with RO for DS reconcentration) for wastewater treatment has been demonstrated to be very effective at rejecting TOrCs and nutrients that may otherwise contaminate the final potable product water if only one physical barrier is implemented [23].

Though the hybrid UFO-MBR is a much newer treatment technology than FAT, conducting an LCA on the UFO-MBR and comparing the life-cycle impacts to FAT can be useful in determining if the UFO-MBR can be a competitive advanced water treatment process in terms of overall environmental impact. Thus, the environmental impacts of hybrid UFO-MBR and FAT for water reuse are the focus of this manuscript.

\section{Material and methods}

Life cycle energy use and environmental impacts of potable reuse using two different treatment schemes were evaluated. Energy demand, construction materials, and chemical use were input into an LCA model. Outputs from the LCA were based on material 
acquisition/production and plant operation, including energy use, GHG emissions (in carbon dioxide equivalents $\left(\mathrm{CO}_{2} \mathrm{e}\right)$ ), carbon monoxide (CO), volatile organic compounds (VOCs), particulate matter $(\mathrm{PM})$, and nitrogen oxides $\left(\mathrm{NO}_{\mathrm{x}}\right)$.

\subsection{Objectives and scope}

The main objective of this study is to compare the energy use, GHG emissions, and other environmentally relevant emissions of two potential potable reuse technologies using an LCA methodology $[7,8]$. The two water reuse treatment systems evaluated were the FAT plant, which includes conventional activated sludge treatment, MF, RO, and UV-AOP and the hybrid UFOMBR, which includes biological treatment, UF, FO, and RO. Other objectives included determining unit processes that contribute the most to the total environmental impact (highest energy demand and GHG emissions) of each system and optimizing the UFO-MBR unit processes based on the findings of the unit process evaluation.

The scope of the LCA encompassed the construction, operation, and maintenance of a FAT and UFO-MBR treatment plant over a 25-year lifetime. The system boundary used to evaluate each treatment scheme only included on-site plant processes. Wastewater collection and treated water distribution piping and pumping were not included in the system boundary. Similarly, nutrient recovery and reuse, which can reduce the environmental impact of wastewater treatment [3, 42, 43], were not included in this study because the main focus was water reuse. Direct emissions from wastewater treatment (e.g., nitrous oxide $\left(\mathrm{N}_{2} \mathrm{O}\right)$ produced during biological nitrogen removal and methane $\left(\mathrm{CH}_{4}\right)$ produced during anaerobic digestion of primary and secondary solids have also been shown to increase the life-cycle impact of wastewater treatment plants $[3,10]$. Direct emissions vary between different biological wastewater treatment schemes and change with the extent of treatment-increasing for systems that achieve very low nitrogen and phosphorous effluent concentrations. Direct emissions were not included in this study because the objective was to evaluate the advanced treatment train for potable water reuse and it was assumed for the purposes of this study that direct emissions from the biological process would be similar for FAT and UFO-MBR treatment.

The functional unit for the LCA was the production of $1 \mathrm{~m}^{3}$ of reusable (potable and/or nonpotable) water. For FAT, this only included the final potable water that was treated through the full treatment train. RO concentrate was considered to be a waste stream and was not included in 
the functional unit. Two reuse streams were included in the functional unit of the UFO-MBR LCA: potable water treated through the FO and RO membranes, and non-potable water extracted from the activated sludge through the UF membranes. The life-cycle impact of wastewater treatment is affected by the effluent quality (potable or non-potable); thus, the environmental impact of MBR and UF treatment will be lower than the environmental impact of FAT. However, it is important to include the UF permeate as part of the functional unit because nonpotable water can be a valuable part of the water supply portfolio, offsetting demand for limited potable supplies [44]. For example, the California Department of Water Resources reported that residential outdoor water use in Southern California accounts for $20 \%$ to $40 \%$ of the total residential use [15]. The fraction of non-potable water produced through the UF membrane in this study was 33\%, well within the range reported for residential outdoor water use by the California Department of Water Resources. The required potable water quality parameter used in the LCA was a TDS concentration less than $500 \mathrm{mg} / \mathrm{L}$, the U.S. Environmental Protection Agency's (EPA) secondary drinking water standard. The required non-potable water quality parameter was permeate with a TDS concentration of less than 1,000 mg/L, which is within the acceptable range for most turf grass irrigation [45].

The influent and effluent flows, construction materials, and energy and chemical use data for FAT were collected from Orange County Water District's (OCWD) ground water replenishment plant that treats 265,000 $\mathrm{m}^{3} /$ day (70 million gallons per day (MGD)) of secondary treated wastewater effluent to drinking water standards. As part of the OCWD's treatment process, RO concentrate (45,400 $\mathrm{m}^{3} /$ day (12 MGD)) is discharged through an ocean outfall. Concentrate disposal can have an environmental impact, but the impact is difficult to assess because it is highly dependent on the sensitivity of the environment to which the concentrate is discharged [46]. Because the specific and minimally-expected environmental impacts of discharging the concentrate ( 5,000 mg/L TDS) are not known for the metrics used in this study (i.e., energy use and emissions of GHGs, CO, VOCs, PM, and $\mathrm{NO}_{\mathrm{x}}$ ), they were not included in the LCA for the scenario requiring offshore discharge. Concentrate disposal was considered in the LCA for inland FAT scenarios, which may require deep well injection of the concentrate as a primary disposal method [47]. The impact of deep well injection was added to the FAT LCA by calculating the energy demand over a range of injection pressures from 17 to 69 bar ( 250-1000 
psi). A complete description of the energy, material, and chemical inputs used in the LCA analysis for all FAT scenarios (ocean and inland applications) is provided in Section 2.3.

A case-study [48] of the full-scale Nordkanal Wastewater Treatment Plant located in Nordkanal, Germany was used as a basis for the influent flow to the UFO-MBR $\left(48,100 \mathrm{~m}^{3} /\right.$ day (12.7 MGD)) to size the UFO-MBR process tanks and to estimate the energy use of the MBR, including biological treatment, UF membrane filtration, and membrane aeration demand. Energy, material, and chemical inputs for the UFO-MBR's FO and RO treatment processes were determined using operating data from a pilot-scale UFO-MBR [24] and from UFO-MBR, FO, and RO models. The UFO-MBR was modeled at four different DS concentrations (20, 30, 40, and $50 \mathrm{~g} / \mathrm{L} \mathrm{NaCl}$ ) to determine if there was an optimum operating DS concentration to minimize the energy and environmental impacts of the treatment plant. A detailed description of energy, material, and chemical inputs, and modeling software used in the LCA is provided in Sections 2.3, 2.4, and 2.5.

\subsection{Life cycle assessment tool and methodology}

A comprehensive hybrid LCA decision support tool, Wastewater-Energy Sustainability Tool (WWEST), was used to evaluate the energy use and environmental impacts of the FAT and UFO-MBR from 'cradle to grave' [49]. WWEST utilizes an economic input-output LCA (EIOLCA) methodology to assess the impacts of materials acquisition and production, with the exception of most chemicals and a few other specialty materials, and a process-based LCA methodology to assess the impacts of plant construction, operation, energy use, maintenance, and production of specialty materials. The national average electric mix, which is the average U.S. energy production from primary energy sources such as oil, natural gas, and coal, was used to calculate GHG and other environmentally relevant emissions from plant construction, operations, and energy use. The main purpose of this study was to compare the life-cycle impact of the two distinct treatment systems, not to capture every possible effect of the two processes. Thus, a consequential LCA approach was used to compare the treatment systems. A full description of the LCA methodology used in WWEST is provided by Stokes and Horvath [50]. In place of an independent review by an LCA practitioner, two LCA experts (Leslie Miller-Robbie and Jennifer R. Stokes) contributed to this study. Dr. Miller-Robbie and Dr. Stokes together have over 20 years of experience conducting and reviewing LCAs of urban water systems (e.g., [4, 51-54]). 


\subsection{Modeling tools: ROSA, FOROSA, ERI, and OMBR sizing model}

Several models were used in calculating the energy and sizing a full-scale UFO-MBR. Water flux and reverse salt flux through the FO membranes were calculated using a novel forward osmosis - reverse osmosis system analysis (FOROSA) program [55]. Bioreactor solute concentrations and FO membrane area were determined using a UFO-MBR model developed and presented in a previous publication [24]. Reverse osmosis system analysis (ROSA) program (Dow Filmtec, Edina, MN) and an energy recovery device model (PX Power Model, ERI, San Francisco, CA) were used in parallel to determine RO membrane area requirements and RO energy demand. A description of each model is provided in the following sub-sections.

\subsubsection{FO performance model (FOROSA)}

FOROSA is a first-of-its-kind integrated FO-RO modeling software developed at the Colorado School of Mines (Golden, CO) that uses iterative optimization techniques to model water and solute fluxes based on user inputs, membrane characteristics (e.g., membrane water permeability, solute permeability, solute resistance, membrane area), and solution chemistry (e.g., feed solution and DS solute compositions and concentrations). Water flux is modeled in FOROSA using equations developed by McCutcheon and Elimelech [42, 56] with modifications proposed by Cath et al. [57]. The water flux equation embedded in the model accounts for internal and external concentration polarization as defined by Equation 1:

$J_{w}=A_{t}\left(\pi_{D} \exp \left(-J_{w} K\right)-\pi_{F} \exp \left(-\frac{J_{w}}{k}\right)\right)$

where $J_{w}$ is the water flux, $A_{t}$ is the water permeability coefficient, $\pi_{D}$ is the osmotic pressure of the bulk DS and $\pi_{F}$ is the osmotic pressure of the bulk feed solution, $K$ is the resistance to solute diffusion in the membrane support layer, and $k$ is the external mass transfer coefficient. Fouling effects can also be evaluated in FOROSA but were not directly considered in the current study because the extent of FO membrane fouling over long-term operation is still unknown. Membrane fouling was indirectly included in the LCA for UFO-MBR and FAT treatment through chemical cleaning and membrane replacement intervals.

Reverse solute flux $\left(\mathrm{J}_{\mathrm{S}}\right)$ is modeled in FOROSA using a mass balance approach. $\mathrm{J}_{\mathrm{S}}$ is calculated in series, first through the porous support layer then through the semi-permeable 
active layer, using an equation similar to that developed by Phillip et al. [58] and defined by Equation 2:

$J_{S}=\frac{J_{W} C_{D}}{1-\left(1+\frac{J_{w}}{B}\right) \exp \left(\frac{J_{w} S}{D}\right)}$

where $C_{D}$ is the bulk DS concentration, $B$ is the active layer solute permeability coefficient, $D$ is the diffusion coefficient of the solute, and $S$ is the structural parameter of the membrane support layer [57]. The parameters used to model the water flux and solute flux for each DS concentration studied using lower and higher permeability membranes are summarized in Table S1 of the Supplemental Information.

\subsubsection{UFO-MBR sizing model}

A UFO-MBR model, described in a previous publication [24], was used to calculate the expected bioreactor salinity with one-third of the flow extracted through the UF membranes and two-thirds of the flow treated through the FO membranes. For the current study, the UFO-MBR model was extended to calculate the FO membrane area, estimate the number of FO plate-andframe cassettes, required DS flowrate, and concentration of the DS flowing out of the FO membrane elements. The FO membrane area was calculated using the average water flux

determined by FOROSA and the specified potable water production rate $\left(32,100 \mathrm{~m}^{3} /\right.$ day $(8.5$ MGD)). The number of plate-and-frame cassettes was determined using the calculated membrane area and an assumed total plate height of $4 \mathrm{~m}$ (three 1.3-m plates stacked vertically and operated in series) and width of $0.6 \mathrm{~m}$; these dimensions were selected based on current UF and MF submerged plate-and-frame cassette design [59]. The number of plates was used to calculate the required DS flowrate assuming an inlet DS flow $0.2 \mathrm{~L} / \mathrm{min}$ per plate. The low inlet DS flowrate $(0.2 \mathrm{~L} / \mathrm{min})$ was chosen using the operating DS flowrate from our pilot-scale UFOMBR [24] and to account for the increase in DS flow through the full-scale plates as water is absorbed from the feed into the DS during UFO-MBR operation. The width of the plates installed on the pilot-scale UFO-MBR are approximately $0.3 \mathrm{~m}$ (half of the width of the fullscale plates) but are much shorter $(0.6 \mathrm{~m})$ than the plates designed in this study. Thus, the initial cross-flow velocity through the larger plates would be about half of the cross-flow velocity used in the pilot-scale system but the exit DS flow rate and cross-flow velocity would be three to five times higher (depending on the DS concentration) than the initial cross-flow velocity as water is 
drawn into the DS across the much longer full-scale plates. The DS concentration flowing out of the FO membrane cassettes was determined for inlet DS concentrations of 20, 30, 40, or $50 \mathrm{~g} / \mathrm{L}$ $\mathrm{NaCl}$ using a simple mass balance that included the calculated DS flowrate, water permeation rate, and inlet DS concentration.

\subsubsection{RO sizing and energy recovery device modeling}

The ROSA RO system design software was used to size and evaluate the performance of pilot- and full-scale RO systems. The DS flowrate and concentration after FO membrane treatment (calculated with the UFO-MBR model) were used as inputs to ROSA. The RO system design (number of stages, pressure vessels, and membrane elements) were used in ROSA to meet three design requirements: RO brine concentration of 20, 30, 40, or $50 \mathrm{~g} / \mathrm{L} \mathrm{NaCl}$, RO permeate flowrate of 32,100 $\mathrm{m}^{3} /$ day (8.5 MGD), and RO permeate $\mathrm{NaCl}$ concentration of less than 500 $\mathrm{mg} / \mathrm{L}$ (the EPA secondary drinking water standard). RO membrane selection varied based on the DS concentration. RO permeate $\mathrm{NaCl}$ concentrations of less than $500 \mathrm{mg} / \mathrm{L}$ could be met using brackish-water membranes (BW30HR-440i, Dow Filmtec) for RO brine concentrations of 20, 30, and $40 \mathrm{~g} / \mathrm{L} \mathrm{NaCl}$, but a mix of brackish-water and seawater membranes (SW30XLE-440i) was required to achieve an RO permeate concentration of less than $500 \mathrm{mg} / \mathrm{L}$ for the system modeled with RO brine concentration of $50 \mathrm{~g} / \mathrm{L} \mathrm{NaCl}$. The ROSA inputs, outputs, and system design for each concentration of the RO brine are summarized in Table S2 of the Supplementary Information.

The outputs from ROSA were used as inputs to a power model of an energy recovery device [60]. The energy recovery device used in the power model was a pressure exchanger (PX-Q300, ERI); the purpose of the pressure exchanger is to transfer energy from the high-pressure RO concentrate to the low-pressure $\mathrm{RO}$ feed. User inputs include RO feed pressure and salt concentration, RO concentrate pressure and salt concentration, and RO system recovery. Energy recovery and system design were optimized in the energy recovery model by adjusting the number of pressure exchangers included in the design. The inputs and outputs of the energy recovery model for each DS concentration are shown in Figs. S1 through S4 of the Supplementary Information.

\subsection{FAT facility: description and inventory analysis}


The OCWD ground water replenishment plant receives secondary treated wastewater from an adjacent conventional wastewater treatment facility. The secondary effluent is first filtered through 17,784 submerged polypropylene MF membrane bundles followed by low-pressure RO and UV-AOP. The RO system comprises 2250 pressure vessels containing 7 spiral-wound membrane elements in each vessel; the recovery of the RO system is approximately $85 \%$. The UV-AOP system contains 3,888 low-pressure UV lamps installed in 27 pressure vessels, and the applied UV dose is $500 \mathrm{~mJ} / \mathrm{cm}^{2}$. A schematic drawing of the FAT unit processes, system boundary, LCA inputs, and process flows is shown in Fig. 1.

\subsubsection{Energy demand}

OCWD provided energy, chemical use, and construction material data for their FAT plant but they did not have data on the conventional treatment facility that provides the secondary effluent feed for the FAT. Therefore, conventional treatment energy demand was estimated using data from similarly-sized treatment facilities [61, 62]. The energy data provided by OCWD and illustrated in Fig. 1 was used for the base case FAT scenario: a facility that discharges the RO brine through an ocean outfall. No energy demand for brine disposal was included for the base case FAT scenario; however, four other FAT scenarios were analyzed for inland applications, disposing of the brine using deep-well injection. The energy demand for deep well injection was calculated over a range of injection pressures of 17, 34, 52, and 69 bar (250, 500, 750, and 1000 psi) and at a daily brine flow of 45,400 $\mathrm{m}^{3} /$ day (12 MGD). The power requirement for brine disposal and total FAT energy demand for brine disposal pressures ranging from 0 to 69 bar are summarized in Table 1.

Table 1. Summary of power required for RO brine disposal and life-cycle energy use of FAT at brine disposal pressures of 0,17, 34, 52, and 69 bar

\begin{tabular}{c|c|c}
\hline Disposal pressure, bar (psi) & Disposal power requirement, $\mathbf{k W}$ & Life-cycle FAT energy use, $\mathbf{~} \mathbf{W h} / \mathbf{m}^{\mathbf{3}}$ \\
\hline $0(0)$ & 0 & 1.1 \\
\hline $17(250)$ & 1,200 & 1.2 \\
\hline $34(500)$ & 2,300 & 1.3 \\
\hline $52(750)$ & 3,500 & 1.4 \\
\hline $69(1000)$ & 4,700 & 1.5 \\
\hline
\end{tabular}




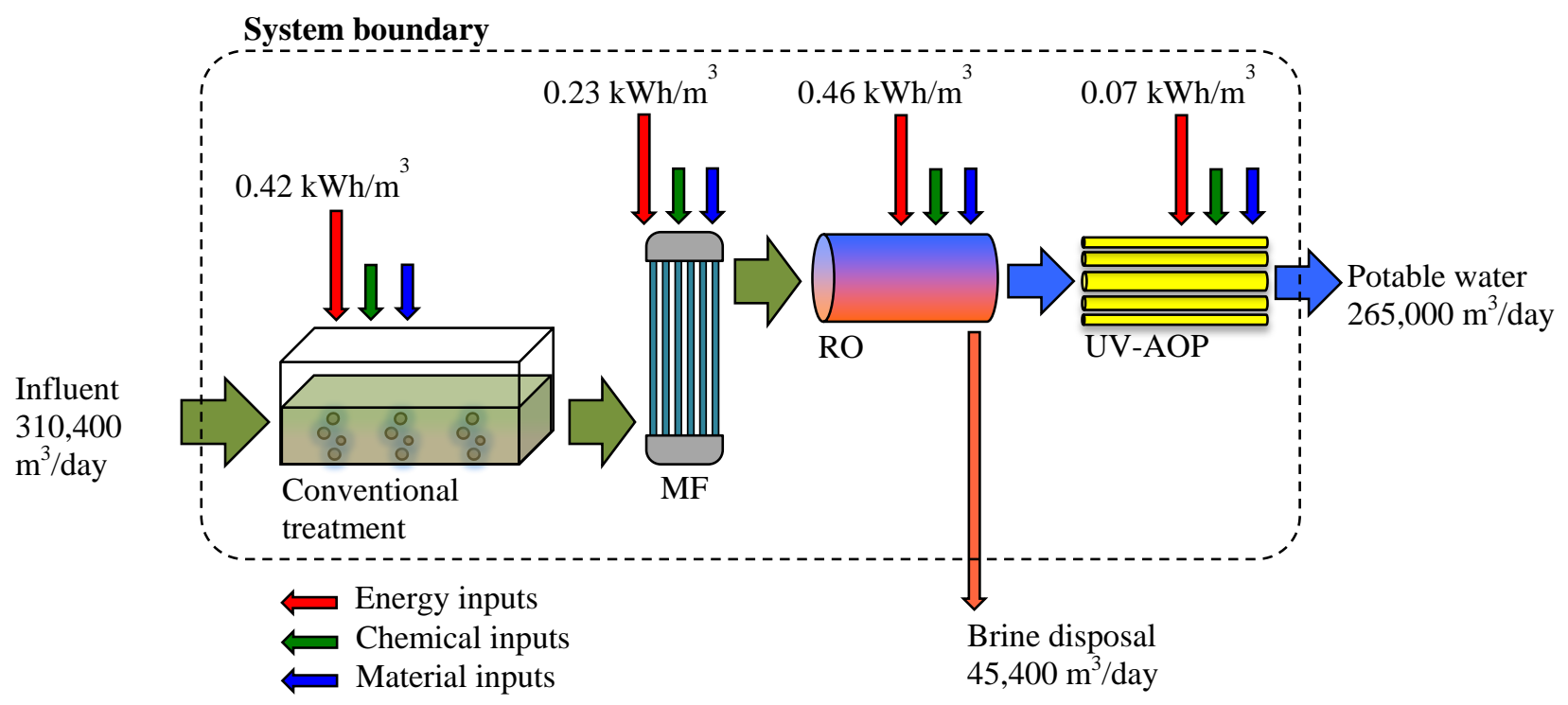

Fig. 1. Schematic drawing of system boundary, flows, unit processes, and energy, materials, and chemical inputs used for the LCA of the FAT plant.

\subsubsection{Chemical use}

Various chemicals are used in FAT facilities to clean membranes and UV lamps, to adjust the $\mathrm{pH}$, and to add alkalinity to the RO permeate. Many of these chemicals (e.g., calcium hydroxide, citric acid, sodium hydroxide, sulfuric acid, and hydrogen peroxide) were included in the LCA; however, a few of these chemicals (e.g., anti-scalants and certain membrane cleaning solutions) are proprietary and data needed to include them in the LCA are not readily available. OCWD does not have data for chemicals (e.g., coagulants, polymers, and organic carbon) used in the conventional treatment plant providing the secondary effluent for FAT; therefore, they were not included in the FAT LCA. Chemicals used for conventional/activated sludge treatment were also excluded from the UFO-MBR LCA to ensure that the chemicals input into the LCA of both systems were only related to advanced treatment. The omission of chemical use for conventional treatment may slightly decrease the calculated environmental impact of FAT and UFO-MBR treatment, but the effect should only be marginal because energy use, which was included in the LCA, has been shown to be the major contributor to the life-cycle impact of conventional wastewater treatment [9, 42, 52]. Chemicals evaluated for each FAT unit process (MF, RO, and UV-AOP) and the amount used are summarized in Table 2. 
Table 2. Summary of chemical inputs for each FAT unit processes

\begin{tabular}{c|c}
\hline \multicolumn{2}{c}{ MF } \\
\hline Chemical & Use, $\mathbf{g} / \mathbf{m}^{\mathbf{3}}$ \\
\hline Calcium hydroxide & 15 \\
\hline Citric acid & 0.2 \\
\hline \multicolumn{2}{c}{ Rodium hydroxide } \\
\hline \multicolumn{2}{c}{ UV-AOP } \\
\hline Codium hypochlorite & Use, $\mathbf{g} / \mathbf{m}^{\mathbf{3}}$ \\
\hline Sulfuric acid & 11 \\
\hline \multicolumn{2}{c}{ UV-A } \\
\hline Chemical & Use, $\mathbf{g} / \mathbf{m}^{\mathbf{3}}$ \\
\hline Hydrogen peroxide & 3 \\
\hline
\end{tabular}

\subsubsection{Inventory of construction material}

The inventory of construction material was estimated for conventional treatment and provided by OCWD for the FAT facility. Sizing of the conventional treatment clarifiers and activated sludge basins was completed using general sizing assumptions for wastewater treatment plants from Metcalf and Eddy [63]—-these values are embedded in WWEST. The material inventory for the FAT plant was limited to process piping and pumps, basin dimensions for submerged MF treatment, membrane and membrane housings (MF cassettes and RO pressure vessels), and UV lamps and lamp housings. The materials entered into WWEST were selected carefully to ensure that similar components were represented comparably for the FAT and UFOMBR treatment plants. Using this material input method guaranteed that neither of the potable reuse treatment schemes would be weighted unfairly against the other and is consistent with the principles of consequential LCA. Details of material inputs into WWEST for the FAT plant are summarized in Table S3 of the Supplemental Information.

\subsection{UFO-MBR treatment facility description and inventory analysis}

The capacity of the largest known UFO-MBR system treating municipal wastewater is approximately $300 \mathrm{~L} /$ day (80 gal/day) [24]. It would be inappropriate to use energy and sizing data from a small pilot-scale system as inputs to an LCA if the purpose of the LCA is to compare the energy use and environmental impacts of the UFO-MBR system with a full-scale treatment facility. Therefore, the energy use, chemical use, and material inventory for a full-scale UFOMBR system were estimated using data from a real-world full-scale MBR system combined with UFO-MBR pilot data and UFO-MBR, FO, and RO modeling results. The MBR data chosen for 
the UFO-MBR LCA were from a case study conducted for the Nordkanal Wastewater Treatment Plant [48]. This case study was selected because it was one of the most well documented MBR systems and had fairly high treatment plant capacity (48,100 $\mathrm{m}^{3} /$ day). The smaller scale used for UFO-MBR treatment compared to the larger scale used for FAT $\left(48,100 \mathrm{~m}^{3} /\right.$ day compared to $310,400 \mathrm{~m}^{3} /$ day) may over-estimate the life-cycle impact of UFO-MBR treatment because of economy of scale [64]. In spite of this potential, data from the Nordkanal Wastewater Treatment Plant were chosen because of the overall completeness of the plant data.

In the UFO-MBR the flow from the bioreactors is split between FO membrane treatment for potable reuse and UF membrane treatment for non-potable reuse. The flow split that was selected for the full-scale UFO-MBR design was two-thirds treated through the FO membranes and onethird treated through UF membrane. In real UFO-MBR systems the flow split can be adjusted to achieve different UF permeate water qualities. For the flow split chosen for this study the TDS concentration in the bioreactors and UF permeate are approximately $1 \mathrm{~g} / \mathrm{L}$ (determined through UFO-MBR pilot testing and modeling) [24]. It is important to note that a substantial change in this flow split would likely affect the results of the LCA for UFO-MBR treatment. The scope of the current study was to evaluate one flow split; however, assessing the environmental impact as a function of the flow split would be insightful and should be part of future UFO-MBR studies.

Submerged hollow-fiber polyvinylidene fluoride (PVDF) membranes were selected for the LCA and the membrane area was sized assuming an average water flux of $20 \mathrm{~L} / \mathrm{m}^{2} / \mathrm{hr}$ (LMH). Submerged FO membrane cassettes were sized using the modeling approach described in Section 2.3.2. The FO and RO membrane area, RO energy demand, and RO system recovery were calculated for DS concentrations of 20,30,40, and $50 \mathrm{~g} / \mathrm{L} \mathrm{NaCl}$ using the models described in Section 2.3. A schematic drawing of the UFO-MBR unit processes, system boundary, LCA inputs, and process flows is provided in Fig. 2. 


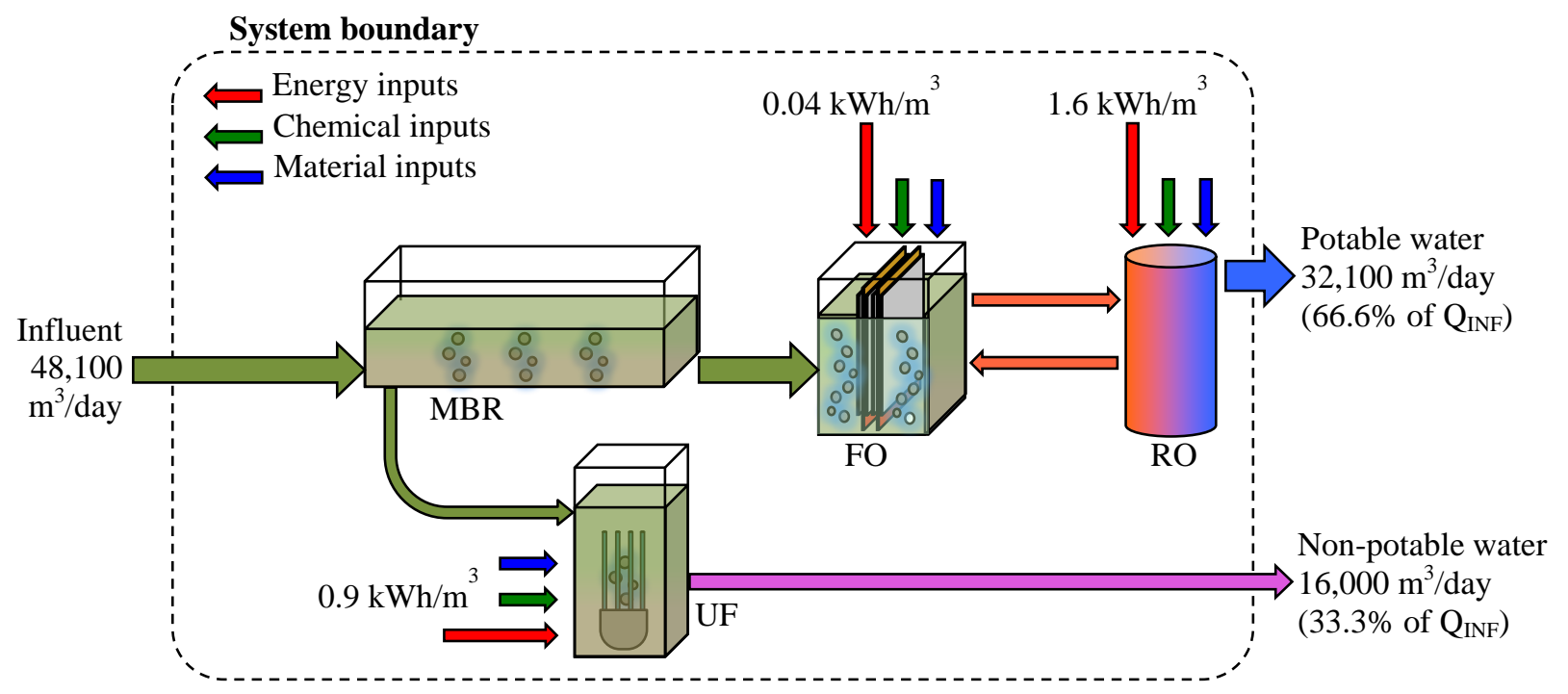

Fig. 2. Schematic drawing of system boundary, flows, unit processes, and energy, materials, and chemical inputs used for the LCA of a UFO-MBR treatment plant. The illustrated RO power is for an RO system without energy recovery, producing an RO brine of $40 \mathrm{~g} / \mathrm{L} \mathrm{NaCl}$. The energy usage for the MBR component (activated sludge and UF/FO membrane aeration) of the UFOMBR is included in the UF energy.

\subsubsection{Energy demand}

The energy demand of the UFO-MBR process was calculated for the MBR, FO DS pumping, RO reconcentration, and UFO-MBR material acquisition and production. The MBR energy demand was assumed to be $0.9 \mathrm{kWh} / \mathrm{m}^{3}$, which was the average annual energy demand reported for the MBR at Nordkanal [48]. The MBR energy used in the LCA includes pumping, bioreactor aeration, membrane aeration, and UF permeate pumping. The membrane aeration was assumed to be the same for submerged UF and FO membranes. This is a conservative assumption because recent studies have demonstrated that FO membrane air-scour requirements are less than those for UF and MF MBRs [24, 25]. Luo et al. [25] reported that the air-scour requirement for OMBRs is about half of that required for MBRs and the air-scour rates used by Holloway et al. [24] for OMBR membrane aeration were much less than those used for porous MF and UF membrane MBRs: $1.5 \mathrm{~m}^{3}$ of air per $\mathrm{m}^{2}$ of membrane per hour for OMBR treatment compared to $15 \mathrm{~m}^{3} / \mathrm{m}^{2} / \mathrm{hr}$ for MBRs [48]. FO DS pumping requirements were calculated for a DS flowrate between 6,400 and 15,500 L/min (dependent on required membrane area and number of submerged FO plate-and-frame cassettes) and a DS vacuum pressure of 0.2 bar. The DS must be pumped under vacuum through submerged FO membrane cassettes to prevent the flat-sheet FO membranes from stretching away from the DS channel into the feed channel. RO power 
requirements were calculated using the ROSA program to produce RO brine (DS) concentrations of 20, 30, 40, and $50 \mathrm{~g} / \mathrm{L} \mathrm{NaCl}$. RO power was also calculated for each DS concentration with an energy recovery device (pressure exchanger) installed on the RO system using proprietary modeling software developed by ERI. RO power and total UFO-MBR energy for DS concentrations of 20,30, 40, and $50 \mathrm{~g} / \mathrm{L} \mathrm{NaCl}$ with and without $\mathrm{RO}$ energy recovery are summarized in Table 3.

Table 3. Summary of RO energy requirements for DS reconcentration and total energy of UFOMBR treatment at DS concentrations of 20,30,40, and $50 \mathrm{~g} / \mathrm{L} \mathrm{NaCl}$, with and without $\mathrm{RO}$ energy recovery. RO energy calculated using water produced through RO system only. Total UFO-MBR energy calculated with water produced through RO and UF systems

\begin{tabular}{c|c|c}
\hline \multicolumn{3}{c}{ UFO-MBR without and (with) energy recovery device } \\
\hline DS concentration, g/L & RO energy, $\mathbf{~ W h} / \mathbf{m}^{\mathbf{3}}$ & Total UFO-MBR energy, $\mathbf{~ k W h} / \mathbf{m}^{\mathbf{3}}$ \\
\hline 20 & $2.2(1.3)$ & $2.8(2.2)$ \\
\hline 30 & $2.2(1.5)$ & $2.9(2.3)$ \\
\hline 40 & $2.4(1.6)$ & $3.0(2.5)$ \\
\hline 50 & $3.1(2.2)$ & $3.4(2.8)$ \\
\hline
\end{tabular}

\subsubsection{Chemical use}

Chemical use data input into the WWEST model for the UFO-MBR included sodium hypochlorite for UF membrane cleaning and sodium chloride for the DS. Sodium hypochlorite use was calculated assuming that the UF membranes would be chemically cleaned for $30 \mathrm{~min}$ once per week, at a backwash flow rate of approximately 1,700 L/min and a sodium hypochlorite concentration of $0.5 \mathrm{~g} / \mathrm{L}$, the manufacturer recommended sodium hypochlorite cleaning concentration [65]. The sodium chloride use was calculated using the modeled salt loss through the FO and RO membranes at DS concentrations of 20, 30, 40, and $50 \mathrm{~g} / \mathrm{L} \mathrm{NaCl}$. The FO salt loss was modeled using FOROSA for a lower permeability cellulose triacetate (CTA) membrane (permeability of $0.34 \mathrm{LMH} / \mathrm{bar}$ ) and a higher permeability CTA membrane (permeability of 0.68 $\mathrm{LMH} / \mathrm{bar}$ ). The value used for the lower and higher permeability CTA membrane was selected based on the permeability of current and next generation CTA membranes that were referenced by Hancock et al. [44]. Salt loss through the RO membranes was modeled using ROSA for RO brine concentrations of 20, 30, 40, and $50 \mathrm{~g} / \mathrm{L} \mathrm{NaCl}$. Because emission factors for sodium chloride production are not included in WWEST, data from the GaBi 6.0 PE International database [46] was obtained and entered into WWEST. Sodium hypochlorite and sodium chloride use input into WWEST for the UFO-MBR are summarized in Table 4. 
Table 4. Summary of chemical inputs for each UFO-MBR unit process at DS concentrations of 20, 30, 40, and $50 \mathrm{~g} / \mathrm{L} \mathrm{NaCl}$ and for lower and higher permeability CTA membranes

\begin{tabular}{|c|c|c|}
\hline \multicolumn{3}{|c|}{ UF } \\
\hline \multicolumn{2}{|c|}{ Chemical } & Use, $g / \mathrm{m}^{3}$ \\
\hline \multicolumn{2}{|c|}{ Sodium hypochlorite } & 0.1 \\
\hline \multicolumn{3}{|c|}{ FO } \\
\hline \multicolumn{3}{|c|}{ Low permeability membrane } \\
\hline DS conc., g/L & Chemical & Use, $g / \mathrm{m}^{3}$ \\
\hline 20 & Sodium chloride & 640 \\
\hline 30 & Sodium chloride & 490 \\
\hline 40 & Sodium chloride & 400 \\
\hline 50 & Sodium chloride & 350 \\
\hline \multicolumn{3}{|c|}{ High permeability membrane } \\
\hline DS conc., g/L & Chemical & Use, $g / \mathrm{m}^{3}$ \\
\hline 20 & Sodium chloride & 400 \\
\hline 30 & Sodium chloride & 329 \\
\hline 40 & Sodium chloride & 260 \\
\hline 50 & Sodium chloride & 230 \\
\hline \multicolumn{3}{|c|}{ RO } \\
\hline DS conc., g/L & Chemical & Use, $g / \mathrm{m}^{3}$ \\
\hline 20 & Sodium chloride & 100 \\
\hline 30 & Sodium chloride & 230 \\
\hline 40 & Sodium chloride & 490 \\
\hline 50 & Sodium chloride & 500 \\
\hline
\end{tabular}

\subsubsection{Construction material inventory}

Several resources were used to estimate the construction material inventory for a full-scale UFO-MBR. The Nordkanal MBR case study was used to select the number and size of bioreactor and membrane tanks [48]. The Nordkanal wastewater treatment plant has three bioreactor tanks with respective volumes of 2,600, 3,600, and 5,600 $\mathrm{m}^{3}$, and one membrane tank with a volume of $1,500 \mathrm{~m}^{3}$. These tank volumes and estimated rectangular tank dimensions were input into WWEST to estimate the amount of materials (e.g., concrete and steel) required to construct each tank. The process pipe data collected from OCWD's FAT facility was used to select the process pipe material and diameter, and estimate the length of process piping needed for a full-scale UFO-MBR system. The required length of each pipe type was calculated using a linear correlation based on the influent flow to each plant. Process piping material inventory was calculated using this method to get a close approximation of GHG emissions and energy use from process piping to be used in a UFO-MBR treatment facility.

Hollow-fiber PVDF UF membranes were selected for the UFO-MBR design. The UF membrane area was calculated using an assumed average flux of $20 \mathrm{LMH}$ and a production rate 
of $16,000 \mathrm{~m}^{3}$ /day (4.2 MGD). The FO membrane material was CTA; the membrane area was estimated for a potable water production rate of 32,100 m³/day (8.5 MGD) using FOROSA and the UFO-MBR model at DS concentrations of 20, 30, 40, and $50 \mathrm{~g} / \mathrm{L}$ and for lower and higher permeability FO membranes. The required RO membrane area and number of pressure vessels for each DS concentration was calculated with ROSA. The construction material inventory input to WWEST for the UFO-MBR is summarized in Table S4 of the Supplementary Information.

\section{Results and discussion}

Full-scale FAT and UFO-MBR treatment facilities were studied for energy use, GHG emissions, and other environmentally relevant emissions using the WWEST LCA program. The results from the LCA for energy use and GHG emissions were separated into two groups: operations and materials. Operations include the electrical energy used for treatment, and materials include the procurement and manufacturing of all construction, equipment, and membrane materials and plant chemical use. The different FAT and UFO-MBR treatment methods for both the operations and materials groups and metrics assessed in this study are summarized below:

- Overall FAT, including conventional treatment, MF, RO, and UV-AOP, was assessed for energy and GHG emissions at RO brine disposal pressures of 0, 17, 34, 52, and 69 bar. Emissions of CO, VOCs, $\mathrm{PM}, \mathrm{SO}_{\mathrm{X}}$, and $\mathrm{NO}_{\mathrm{X}}$ were also calculated for FAT.

- The impact of individual FAT unit processes (conventional treatment, MF, RO, and UVAOP) on energy and GHG emissions were calculated to determine which unit process contributed the most to FAT life-cycle impacts. This was done only for the ocean outfall scenario (concentrate disposal pressure $=0 \mathrm{bar}$ ).

- Overall UFO-MBR treatment (MBR, FO, and RO) was assessed for energy and GHG emissions at DS concentrations of 20, 30, 40, and $50 \mathrm{~g} / \mathrm{L} \mathrm{NaCl}$. Other environmentally relevant emissions were also determined for UFO-MBR treatment. The initial overall UFOMBR life cycle was studied with currently available lower permeability FO membranes and no RO energy recovery.

- The impacts of individual UFO-MBR unit processes (MBR, FO, and RO) on energy and GHG emissions were assessed to determine which unit processes contributed the most to the UFO-MBR life-cycle impacts. This was done only for a DS concentration of $40 \mathrm{~g} / \mathrm{L} \mathrm{NaCl}$. 
- The overall impact of UFO-MBR treatment was re-assessed for energy and GHG emissions using higher permeability FO membranes and RO energy recovery. This assessment was done at DS concentrations of 20, 30, 40, and $50 \mathrm{~g} / \mathrm{L} \mathrm{NaCl}$.

- And finally, the overall impact of UFO-MBR treatment was assessed with UV-AOP to treat the RO permeate for additional pathogen removal. The UV-AOP system was sized using energy, chemical, and material data obtained from OCWD and scaled down for the lower flow used to model the UFO-MBR.

\subsection{FAT overall impact}

Energy and GHG emissions $\left(\mathrm{CO}_{2} \mathrm{e}\right)$ were calculated for a FAT facility producing 265,000 $\mathrm{m}^{3} /$ day of potable water (treating 310,400 $\mathrm{m}^{3} /$ day) having an ocean outfall and deep-well injection for RO brine disposal. Energy and GHG emissions per unit of water produced for FAT plant operation and materials as a function of RO concentrate disposal pressure are shown in Fig. 3.

Energy and GHG emissions for FAT (combined operation and materials) increase linearly with increasing concentrate disposal pressure. The energy and GHG emissions increased from $1,730 \mathrm{~kJ} / \mathrm{m}^{3}$ to $2,130 \mathrm{~kJ} / \mathrm{m}^{3}$ and $1.15 \mathrm{~kg} / \mathrm{m}^{3}$ to $1.5 \mathrm{~kg} / \mathrm{m}^{3}$, respectively, between the ocean outfall scenario (0 bar) and high-pressure concentrate disposal scenario (69 bar). Clearly, the increases in energy and GHG emissions at higher RO concentrate disposal pressures are directly related to the pumping energy of concentrate disposal. As shown in Fig. 3, the energy and GHG emissions for materials are constant across all disposal pressures and do not increase with disposal pressure because only materials for the FAT plant were included in the LCA, which were the same for all disposal scenarios. The energy and GHG emissions for materials would likely be different between FAT scenarios if the infrastructure (pipeline construction and materials) for deep-well injection of the RO concentrate was included.

The operation of FAT accounted for approximately 70\% of the total energy and 75\% of the total GHG emissions for the ocean outfall scenario (0 bar). For FAT evaluated at the highest disposal pressure (69 bar), the contribution of plant operations to the total energy and total GHG emissions was even higher, contributing approximately 75\% to total energy and 80\% to GHG emissions. In several LCA studies assessing wastewater treatment and reuse facilities, energy for plant operation has been shown to have the highest impact on energy and GHG emissions. 
Stokes and Horvath [4] and Vince et al. [5], in separate LCA studies on water supply and reuse, concluded that facility maintenance and construction were minor contributors to the life cycle impacts of a recycled water treatment plant compared to plant operation. Ortiz et al. [6] determined that facility operation accounted for 74 to $84 \%$ of the life cycle impacts of a conventional activated sludge plant with tertiary UF filtration, and facility operation accounted for 66 to 77\% of the life cycle impacts of an MBR that uses submerged UF membranes. Energy used in wastewater treatment has also been demonstrated to contribute to additional environmentally relevant emissions other than GHGs [6]. Emissions of CO, VOC, $\mathrm{SO}_{\mathrm{x}}, \mathrm{PM}$, and $\mathrm{NO}_{\mathrm{x}}$ for FAT as a function of concentrate disposal pressure are shown in Fig. 4.
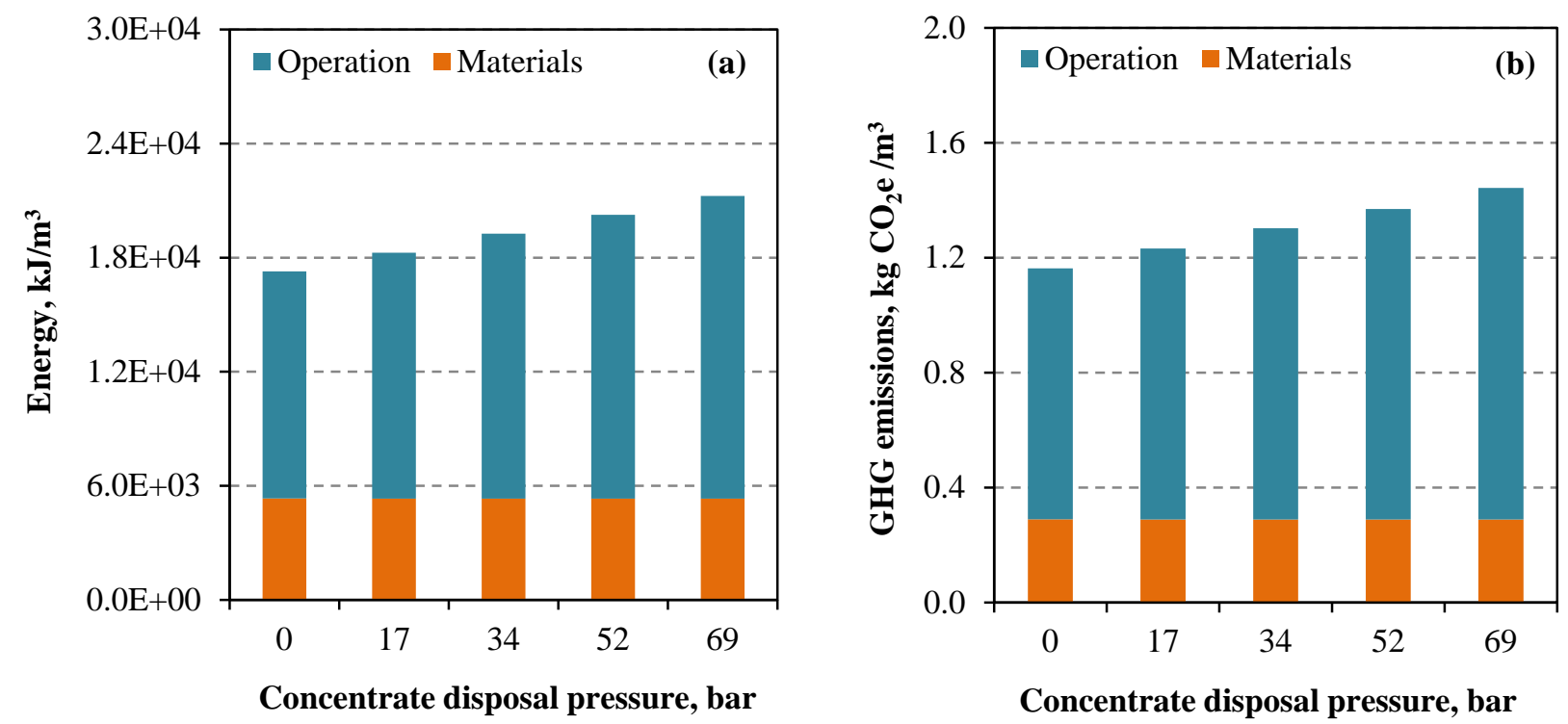

Fig. 3. Life-cycle (a) energy use and (b) GHG emissions $\left(\mathrm{CO}_{2} \mathrm{e}\right)$ as a function of RO concentrate disposal pressure for a full-scale FAT facility treating 310,400 $\mathrm{m}^{3}$ /day and producing 265,000 $\mathrm{m}^{3} /$ day of potable water. 


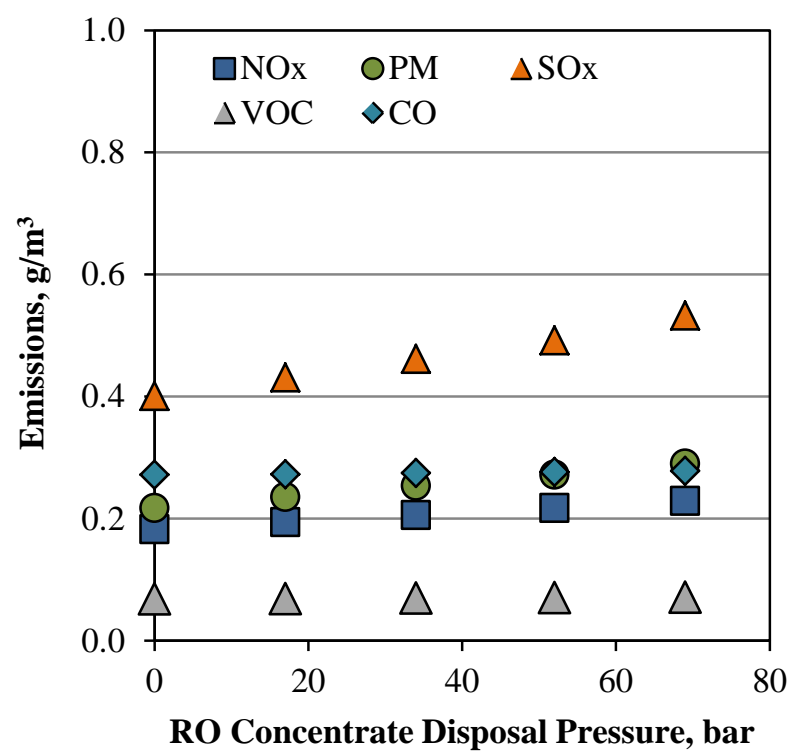

Fig. 4. Life-cycle emissions for FAT plant as a function of RO concentrate disposal pressure.

Although other emissions are lower in magnitude than GHG emissions $\left(g / \mathrm{m}^{3}\right.$ in Fig. 4 compared to $\mathrm{kg} / \mathrm{m}^{3}$ in Fig. $3 \mathrm{~b}$ and consistent with prior literature $\left.[3,6]\right)$, they are still environmentally relevant because these emissions are human health concerns (CO, VOCs, $\mathrm{NO}_{\mathrm{x}}$, and $\mathrm{PM})$, contribute to acidification $\left(\mathrm{SO}_{\mathrm{x}}\right.$ and $\left.\mathrm{NO}_{\mathrm{x}}\right)$, can react in the atmosphere to produce ozone (VOCs and $\mathrm{NO}_{\mathrm{x}}$ ), and are all monitored by the EPA as part of the U.S. Clean Air Act. The emission of these environmentally relevant compounds is mostly related to the energy demand for treatment. This is a common finding from other LCA studies conducted on wastewater treatment plants, which have shown that energy use is the major contributor to emissions and the amount of individual emissions is strongly influenced by the energy mix used to calculate emissions [3]. In this study, emissions of $\mathrm{SO}_{\mathrm{x}}, \mathrm{PM}, \mathrm{NO}_{\mathrm{x}}, \mathrm{CO}$, and VOCs mostly trended with the national average electricity mix used in WWEST, in which $\mathrm{SO}_{\mathrm{x}}(2.9 \mathrm{~g} / \mathrm{kWh})$ and $\mathrm{PM}(1.7$ $\mathrm{g} / \mathrm{kWh}$ ) have substantially higher emission factors compared to $\mathrm{NO}_{\mathrm{x}}(1.1 \mathrm{~g} / \mathrm{kWh}), \mathrm{CO}(0.2$ $\mathrm{g} / \mathrm{kWh})$, and VOCs $(0.07 \mathrm{~g} / \mathrm{kWh})$. The one emission that did not follow this trend is CO, which has the second lowest national average electric mix emission factor but had a calculated emissions value similar to $\mathrm{NO}_{\mathrm{x}}$. This is due to the relatively high emissions factor for $\mathrm{CO}$ from vehicles and gas-powered equipment used in WWEST for plant construction.

\subsection{FAT unit process impacts}


FAT was further assessed for the contribution of each unit process (conventional activated sludge (CON), MF, RO, and UV-AOP treatment) to the total FAT life cycle impact. This assessment was conducted to determine which process had the highest impact on energy use and GHG emissions. Unit processes were only evaluated for the ocean outfall FAT scenario (concentrate disposal pressure of 0 bar). Energy and GHG emissions for each FAT unit process are shown in Fig. 5.

The contribution of each unit process to energy for operation (Fig. 5a) trended closely with the specific energy of the unit processes measured by OCWD (Fig. 1). RO exhibited the highest energy for operation and had the highest specific energy $\left(0.46 \mathrm{kWh} / \mathrm{m}^{3}\right)$. The next highest contributors to energy for operation were conventional treatment, MF, and UV-AOP, which had measured specific energy of $0.42,0.23$, and $0.07 \mathrm{kWh} / \mathrm{m}^{3}$, respectively. RO and MF had the highest impact on energy for materials (Fig. 5a) because of the high membrane area and number of membrane housings (RO pressure vessels and MF cassettes) required for treatment, and high chemical use of each process.

Similar to energy, the contribution of each unit process to GHG emissions from operations trended with the measured unit process specific energy—RO having the highest impact, followed by conventional treatment, MF, and UV-AOP. The impact of each unit process to GHG emissions for materials was comparable to the impact of the unit processes to energy for materials. However, the impacts of the RO and MF unit processes were much closer in GHG emissions from materials compared to the energy from materials. The higher contribution of MF to GHG emissions for materials is due to the global warming potential (GWP) of the chemicals used in OCWD's MF process. Caustic soda and calcium hydroxide have the highest use for MF operation (Table 1) and have a relatively high GWP. The GWP for caustic soda and calcium hydroxide used in WWEST are approximately 4.2 and $1.2 \mathrm{~kg}-\mathrm{CO}_{2} \mathrm{e} / \mathrm{kg}$ of chemical used, respectively. 

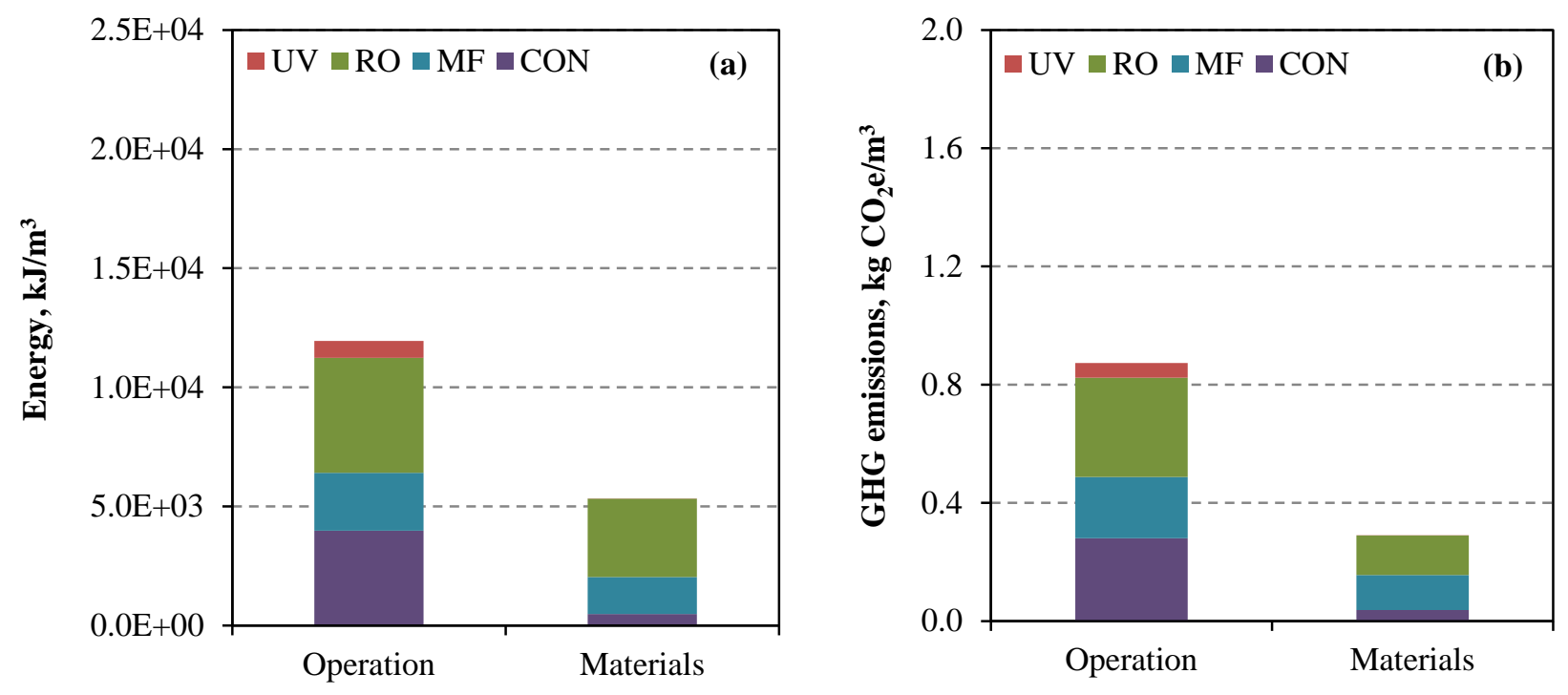

Fig. 5. Life-cycle (a) energy use and (b) GHG emissions $\left(\mathrm{CO}_{2} \mathrm{e}\right)$ for each FAT unit process. Results are for a FAT facility discharging RO concentrate through an ocean outfall (RO concentrate disposal pressure of 0 bar).

\subsection{UFO-MBR overall impact}

UFO-MBR treatment was assessed for energy, GHG emissions, and other environmentally relevant emissions for a facility designed to treat $48,100 \mathrm{~m}^{3} /$ day, producing $32,000 \mathrm{~m}^{3} /$ day of potable water and $16,000 \mathrm{~m}^{3} /$ day of non-potable water suitable for irrigation. The impacts of UFO-MBR treatment were determined for DS concentrations of 20, 30, 40, and $50 \mathrm{~g} / \mathrm{L}$. Energy and GHG emissions as a function of DS concentration were calculated using WWEST and are illustrated in Fig. 6.

Energy (Fig. 6a) and GHG emissions (Fig. 6b) for materials decreased with increasing UFOMBR DS concentration-both are impacted by the large FO membrane area needed to produce $32,100 \mathrm{~m}^{3} /$ day. At low DS concentrations the FO membrane productivity (water flux) is lower, and therefore more FO membrane area is required, and energy and GHG emissions for materials are higher. As a result of the increase in energy and GHG emissions for operations and decrease in energy and GHG emissions for materials at increasing DS concentrations, the optimum DS concentration to operate the UFO-MBR with respect to minimizing energy and GHG emission (operations and materials) is $40 \mathrm{~g} / \mathrm{L} \mathrm{NaCl}$. 

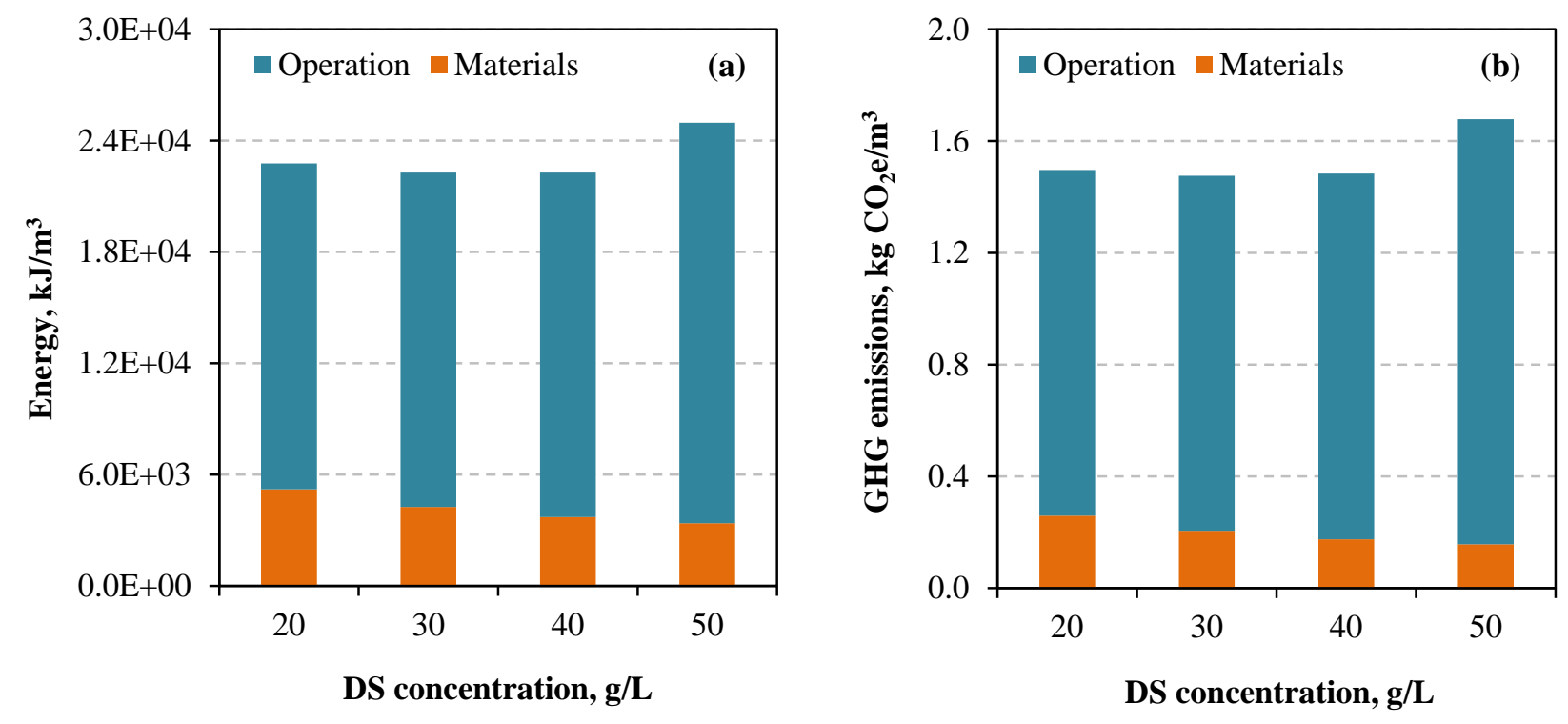

Fig. 6. Life-cycle (a) energy use and (b) GHG emissions $\left(\mathrm{CO}_{2} \mathrm{e}\right)$ as a function of DS concentration for a full-scale UFO-MBR treatment facility.

Energy (Fig. 6a) and GHG emissions (Fig. 6b) for operations slightly increased between DS concentrations of 20 and $40 \mathrm{~g} / \mathrm{L}$ and more substantially increased between DS concentrations of 40 and $50 \mathrm{~g} / \mathrm{L}$. Energy and GHG emissions for operation did not increase as much at the lower DS concentrations because the UFO-MBR's RO system could be designed to operate at lower hydraulic pressures by utilizing low-pressure RO membranes while still achieving the treatment goal (RO permeate TDS $<500 \mathrm{mg} / \mathrm{L}$ ). At a DS concentration of $50 \mathrm{~g} / \mathrm{L}$, a mix of low-pressure and high-pressure RO membranes was needed in the RO system to meet the treatment goal. The use of high-pressure RO membranes substantially increased the hydraulic pressure needed for water production, resulting in much higher RO system specific energy, and increased energy and GHG emissions from operations.

UFO-MBR treatment was also assessed for other environmentally relevant emissions. Emissions of $\mathrm{CO}, \mathrm{VOC}, \mathrm{SO}_{\mathrm{x}}, \mathrm{PM}$, and $\mathrm{NO}_{\mathrm{x}}$ were determined using WWEST as a function of DS concentration for UFO-MBR treatment and are summarized in Fig. 7. 


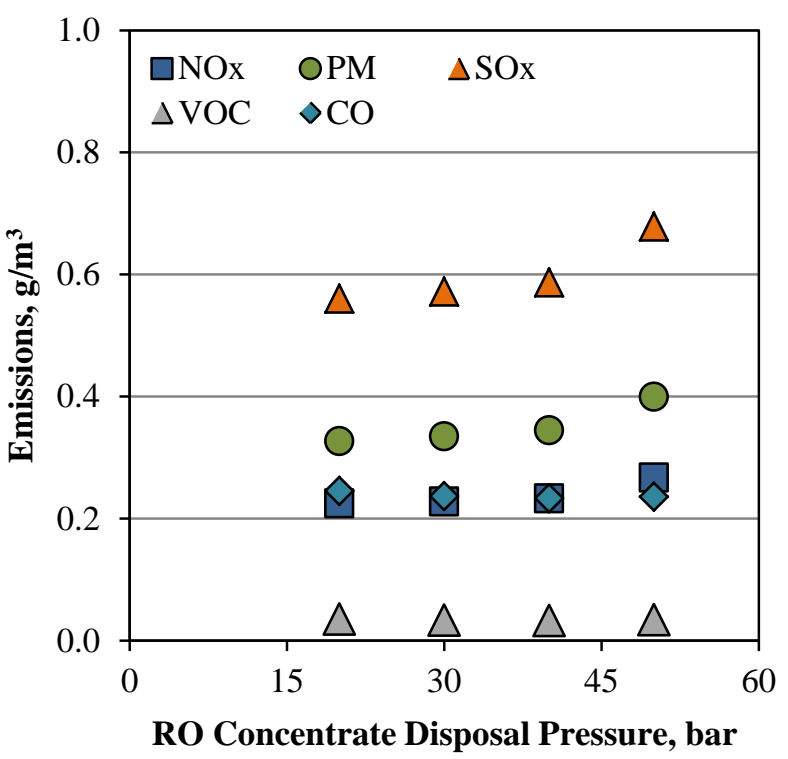

Fig. 7. Life-cycle emissions for UFO-MBR plant as a function of DS concentration.

Life-cycle emissions (Fig. 7) increased with increasing UFO-MBR DS concentration. Similar to the energy use (Fig. 6a) and GHG emissions (Fig. 6b) for operations, other emissions increased slightly between DS concentrations of 20 and $40 \mathrm{~g} / \mathrm{L}$, and increased more sharply between DS concentrations of 40 and $50 \mathrm{~g} / \mathrm{L}$. This trend closely follows the specific energy of UFO-MBR treatment at increasing DS concentrations. The highest calculated specific energy was for a DS concentration of $50 \mathrm{~g} / \mathrm{L}\left(3.4 \mathrm{kWh} / \mathrm{m}^{3}\right)$ followed by DS concentrations of $40 \mathrm{~g} / \mathrm{L}$ $\left(3.0 \mathrm{kWh} / \mathrm{m}^{3}\right), 30 \mathrm{~g} / \mathrm{L}\left(2.9 \mathrm{kWh} / \mathrm{m}^{3}\right)$, and $20 \mathrm{~g} / \mathrm{L}\left(2.8 \mathrm{kWh} / \mathrm{m}^{3}\right)$. As discussed for emissions from FAT, it is not unusual for emissions to be strongly influenced by the energy required for treatment and the energy mix used in the LCA to calculate individual emissions. As such, the highest emissions from UFO-MBR treatment were for $\mathrm{SO}_{\mathrm{x}}$ and $\mathrm{PM}$, which had substantially higher electricity emissions factors in WWEST compared to $\mathrm{NO}_{\mathrm{x}}$, CO, and VOCs.

\subsection{UFO unit process impacts}

UFO-MBR treatment unit processes (MBR, FO, and RO) were analyzed individually for the contribution of each process to the total UFO-MBR life cycle. The unit process analysis was done for the UFO-MBR operating with a DS concentration of $40 \mathrm{~g} / \mathrm{L}$. This concentration was chosen because it had the lowest life-cycle energy use and GHG emissions of any of the UFOMBR DS concentrations studied. The purpose of the unit process analysis was to determine what 
processes had the highest contribution to energy and GHG emissions. Energy use and GHG emissions for each UFO-MBR unit process at a DS concentration of $40 \mathrm{~g} / \mathrm{L}$ are shown in Fig. 8.
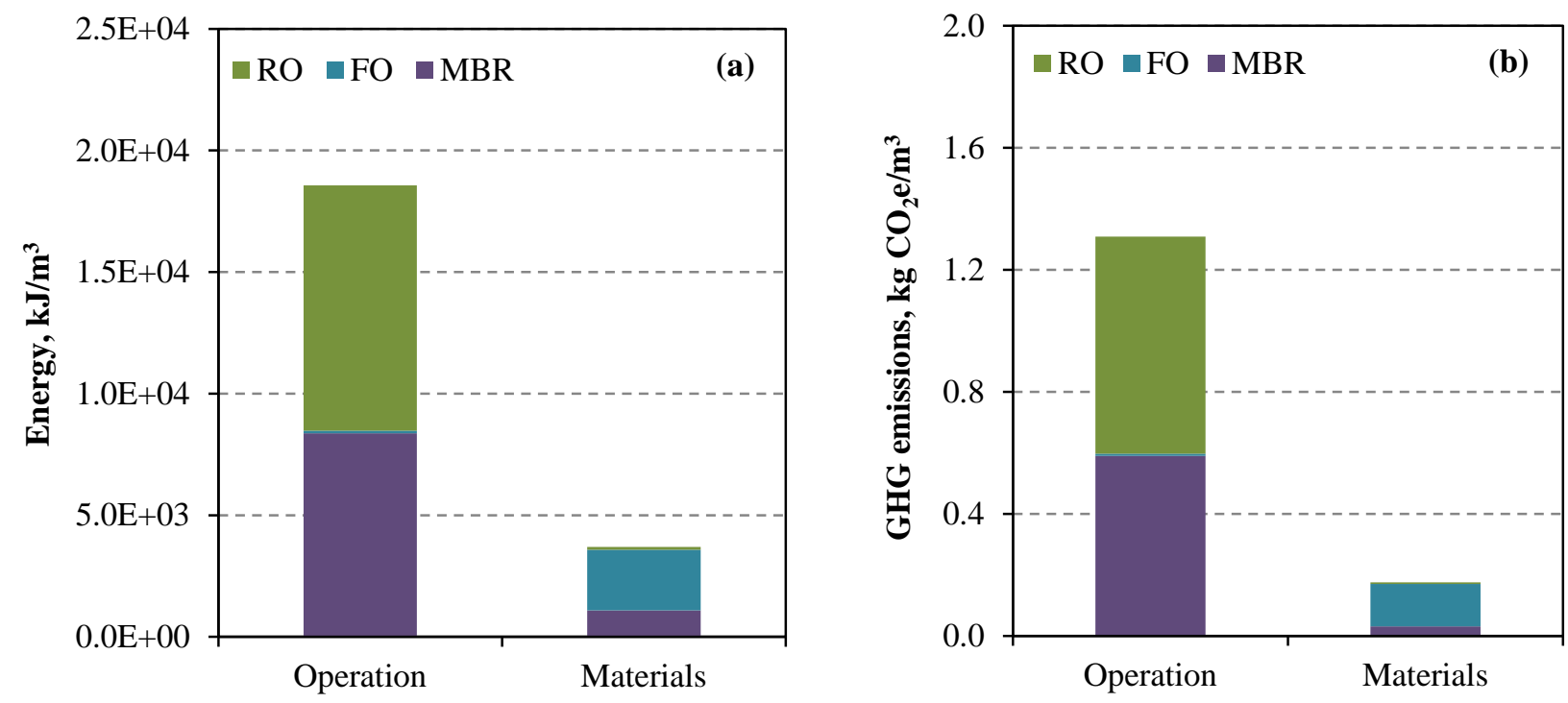

Fig. 8. Life-cycle (a) energy use and (b) GHG emissions $\left(\mathrm{CO}_{2} \mathrm{e}\right)$ for each UFO-MBR unit process. Presented results are for a UFO-MBR operating with a DS concentration of $40 \mathrm{~g} / \mathrm{L}$.

UFO-MBR RO and MBR unit processes were the major contributors to energy use and GHG emissions for operations. These results coincide with the specific energy used in the LCA for the RO, FO, and MBR. RO specific energy (1.6 kWh $/ \mathrm{m}^{3}$, calculated using ROSA) was the highest of the three UFO-MBR unit processes followed by MBR specific energy $\left(0.9 \mathrm{kWh} / \mathrm{m}^{3}\right)$ and FO operation $\left(0.04 \mathrm{kWh} / \mathrm{m}^{3}\right)$. The FO specific energy and energy and GHG emissions for operation are very low because only the energy to pump the DS through the plate-and-frame cassette was included in the FO energy calculation. In reality, energy would also be required for FO membrane air scouring; however, this energy was aggregated into the MBR energy use in the current study.

The FO unit process may provide little contribution to energy use and GHG emissions of operation, but accounted for approximately 67\% of energy use for materials (Fig. 8a) and approximately $79 \%$ of GHG emissions for materials (Fig. 8b). The high contribution of FO to materials is a result of the relatively low permeability of current generation FO membranes and to the low water flux achieved at moderate DS concentrations (e.g., $40 \mathrm{~g} / \mathrm{L}$ ). It is clear from the results in Fig. 8 that RO energy and FO membrane area contribute the most to UFO-MBR energy 
use and GHG emissions and should be reduced to minimize the environmental impact of UFOMBR treatment.

\subsection{UFO optimization}

The minimum energy use $\left(2.3 \times 10^{4} \mathrm{~kJ} / \mathrm{m}^{3}\right)$ and GHG emissions $\left(1.5 \mathrm{~kg} / \mathrm{m}^{3}\right)$ for UFO-MBR treatment were calculated for a system operating with $40 \mathrm{~g} / \mathrm{L} \mathrm{NaCl} \mathrm{DS}$. Although the energy and GHG emissions were lowest at $40 \mathrm{~g} / \mathrm{L}$ DS, the life-cycle energy use of the UFO-MBR was still 24\% higher and GHG emissions were 22\% higher compared to FAT using an ocean outfall for RO concentrate disposal ( 0 bar). The life-cycle energy use of the UFO-MBR was also 6\% higher than the life-cycle energy use for FAT at the highest concentrate disposal pressure (69 bar); however, GHG emissions were very similar for UFO-MBR treatment at $40 \mathrm{~g} / \mathrm{L}$ DS and FAT at a disposal pressure of 69 bar. Hancock et al. [44], using an LCA methodology to compare a hybrid FO system to traditional RO systems for desalination, also found that the impact of FO treatment was higher than more conventional treatment processes. FO membrane development is still relatively new and FO membrane materials are not yet optimized. Research is ongoing and improvements are expected in coming years. In the current study, the area of FO membrane needed for UFO-MBR treatment was the major contributor to the energy use and GHG emissions for materials.

Although FO had the highest contribution to the energy and GHG emissions for materials, it had very little impact on energy and GHG emissions for operations. The highest energy and GHG emissions from operations were for RO system operation. Considering the higher impact of FO to energy and GHG emissions for materials and RO to energy and GHG emissions for operations, UFO-MBR treatment was further assessed using higher permeability FO membranes to reduce the area of FO membrane needed for treatment and RO energy recovery. It is not unreasonable to assume that FO membrane permeability will be higher than that of the CTA membranes used for the base UFO-MBR scenario. Coday et al. [11] recently reported on FO thin-film composite membranes having permeability four times higher than current generation CTA membranes. RO energy was recalculated with an inline pressure recovery device to reduce RO energy use. Energy use and GHG emissions for UFO-MBR treatment (operations and materials) at operating DS concentrations of 20, 30, 40, and $50 \mathrm{~g} / \mathrm{L} \mathrm{NaCl}$ before and after UFOMBR optimization are illustrated in Fig. 9. 
Total energy use (Fig. 9a) and GHG emissions (Fig. 9b) were considerably lower for UFOMBR treatment calculated with more permeable FO membranes and utilization of RO energy recovery. The largest reduction in total energy use and GHG emissions were for operating DS concentrations of 20 and $50 \mathrm{~g} / \mathrm{L}$. Total energy use was reduced by $21 \%$ and total GHG emissions were reduced by $20 \%$ between the initial UFO-MBR life cycle and the optimized UFO-MBR life cycle at a DS concentration of $20 \mathrm{~g} / \mathrm{L}$. Total energy was reduced by $20 \%$ and total GHG emissions were reduced by $17 \%$ between the initial UFO-MBR and optimized UFO-MBR lifecycles at a DS concentration of $50 \mathrm{~g} / \mathrm{L}$. The much lower life-cycle impacts at a DS concentration of $20 \mathrm{~g} / \mathrm{L}$ were due to the reduction in FO membrane area needed for UFO-MBR treatment using more permeable FO membranes. As a result, an optimized UFO-MBR system operating at a DS concentration of $20 \mathrm{~g} / \mathrm{L}$ has the lowest energy and GHG emissions of all UFO-MBR scenarios.
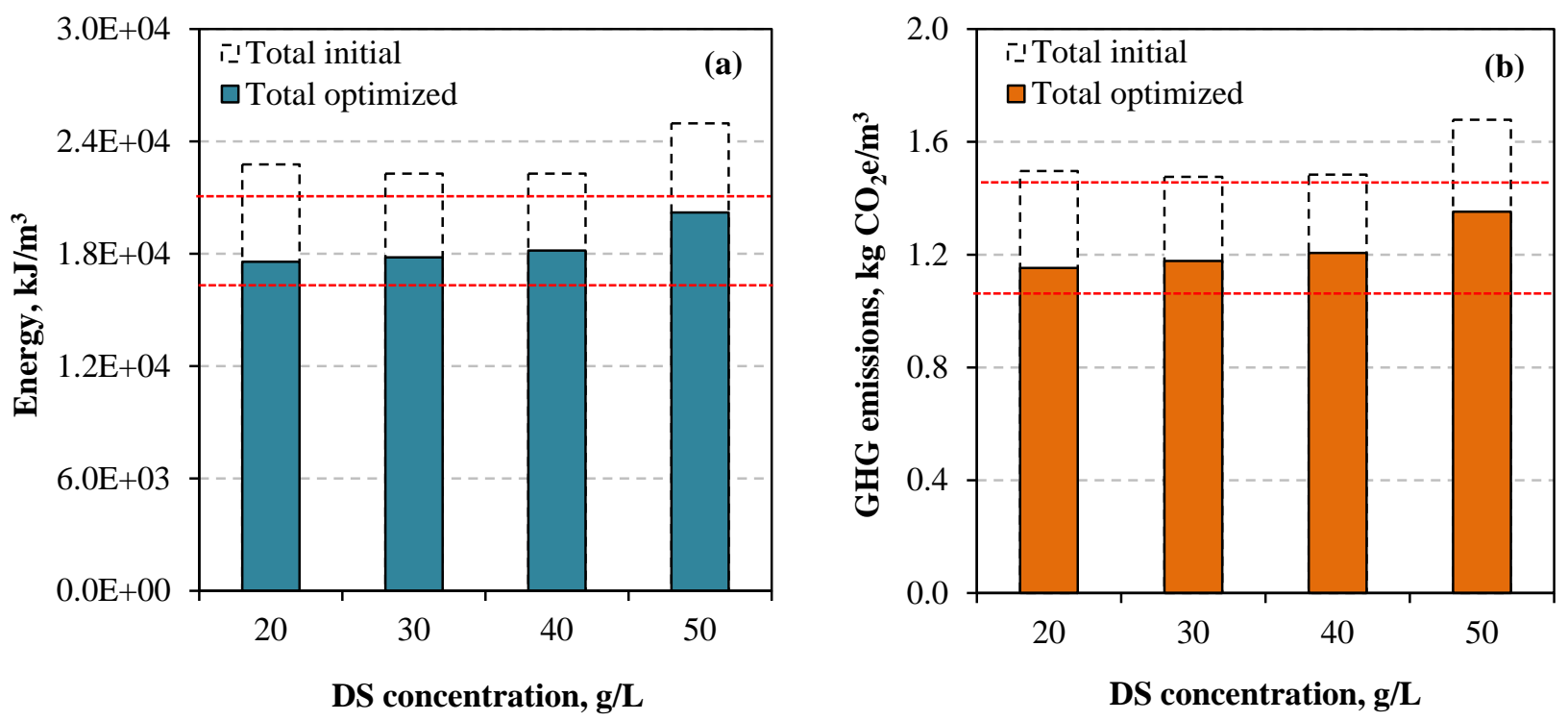

Fig. 9. Total life-cycle (combined operations and materials) (a) energy use and (b) GHG emissions $\left(\mathrm{CO}_{2} \mathrm{e}\right)$ as a function of DS concentration for a full-scale UFO-MBR treatment facility before and after system optimization. Dotted black lines represent the UFO-MBR life cycle before optimization and solid bars represent the UFO-MBR life cycle after optimization. The dotted red lines are the FAT life cycle for the ocean outfall scenario ( 0 bar pressure for concentrate disposal) and for the FAT life cycle at the highest brine disposal pressure (69 bar).

Prior to UFO-MBR optimization, the life-cycle impacts of UFO-MBR treatment were higher than or equivalent to those of FAT at the highest studied concentrate disposal pressure (69 bar) across all DS concentrations studied. The impacts of UFO-MBR treatment were well below 
those of FAT at a concentrate disposal pressure of 69 bar when more permeable membranes and RO energy recovery are utilized. The impacts of UFO-MBR treatment were still higher than those of FAT for the ocean outfall scenario (concentrate disposal pressure of 0 bar), but the impacts for the optimized UFO-MBR at DS concentrations of 20, 30, and $40 \mathrm{~g} / \mathrm{L}$ were much closer to those of the base FAT scenario compared to the initial UFO-MBR life cycle. In fact, the energy use and GHG emissions were only 5\% higher for UFO-MBR treatment at DS concentrations between 20 and $40 \mathrm{~g} / \mathrm{L}$ compared to FAT at the lowest concentrate disposal pressure studied.

\subsection{UFO with $U V-A O P$}

The most important goal of an advanced wastewater treatment system for potable reuse is to protect public health. The FO and RO membranes used in UFO-MBR are excellent barriers to nutrients and TOrCs but the ability of membranes to reliably reject pathogens is still uncertain [66]. In theory, FO and RO membranes capable of rejecting ions should provide a more than adequate barrier to viruses. However, pathogens may pass through the membrane barriers if the membrane or membrane housing are compromised by chemical degradation or mechanical fatigue. The potential for membrane system failure is well recognized by regulators. In Texas, no virus removal credits are granted for RO without integrity and challenge testing [67]. OCWD only receives a 2-log virus removal credit for RO treatment from the California Department of Public Health (CDHP) - the required virus removal for water reuse by CDHP is 12-log. Assuming the UFO-MBR received 1-log virus removal credit for MBR treatment and 4-log virus removal credits for FO and RO membrane treatment (2-log removal credit for FO and RO treatment, respectively) the system would require additional treatment processes to approach 12log removal. One option to increase the log removal of viruses through UFO-MBR treatment is to add UV-AOP, which receives 6-log virus removal credits from CDHP, after RO treatment. Thus, energy and GHG emissions for UFO-MBR treatment with UV-AOP were assessed and are shown in Fig. 10.

The energy use (Fig. 10a) and GHG emissions (Fig. 10b) increase slightly for UFO-MBR treatment with addition of UV-AOP to the treatment process. Given the small increase in the environmental impact and current regulatory climate, including UV-AOP to the UFO-MBR for pathogen removal may be a prudent decision to increase system robustness and ensure the 
public's health is protected. The UFO-MBR may still require system improvements to have lower environmental impacts than FAT for potable reuse, but several advantages to the UFOMBR make it an attractive technology, especially for inland applications. These include 1) no need for RO concentrate disposal, 2) combining FO and UF membrane treatment provides additional operational flexibility for utilities desiring waters of different qualities, 3) FO reduces RO membrane fouling, and 4) using two semi-impermeable barriers (e.g., FO and RO) for wastewater treatment increases system robustness and improves product water quality for potable reuse.
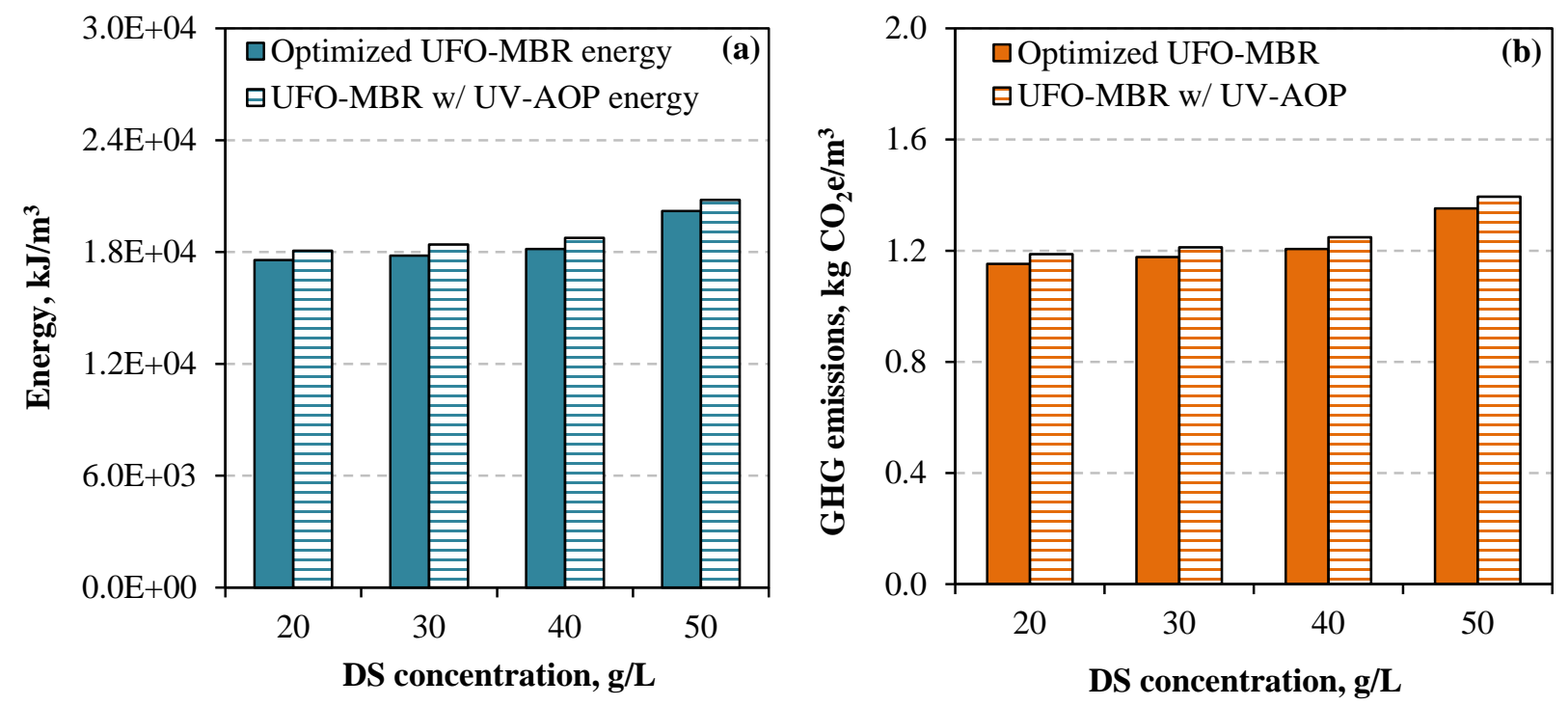

Fig. 10. Total life-cycle (combined operations and materials) (a) energy use and (b) GHG emissions $\left(\mathrm{CO}_{2} \mathrm{e}\right)$ as a function of DS concentration for an optimized full-scale UFO-MBR treatment facility with and without UV-AOP treatment for virus removal.

\section{Conclusions}

The results from the LCA illustrate that the life-cycle impacts of FAT are much lower than UFO-MBR treatment without UFO-MBR system optimization. The major contributor to energy use and GHG emissions of FAT was operations. This is a common finding in LCA studies conducted on water reuse treatment facilities. For FAT, the impacts of energy and GHG emissions for operation were mostly driven by the RO system. Optimization of RO energy use and recovery should be a major emphasis of potable reuse research to reduce the life cycle impacts of FAT. 
The minimum UFO-MBR life-cycle impacts were determined to be at an operating DS concentration of $40 \mathrm{~g} / \mathrm{L}$. The impacts were reduced at this DS concentration because the combined FO membrane area (the major contributor to materials) and RO energy use (the major contributor to operations) were lower than at the other DS concentrations studied. Although the life-cycle impacts were reduced at a DS concentration of $40 \mathrm{~g} / \mathrm{L}$, the UFO-MBR still required optimization to approach the energy use and GHG emissions calculated for FAT. Increasing the FO membrane permeability and adding RO energy recovery resulted in UFO-MBR life-cycle impacts that were much closer to those of FAT and lower than those of FAT requiring deep well injection for RO concentrate disposal. The UFO-MBR life-cycle impacts may have also been lower if nutrient recovery was included and the UFO-MBR was evaluated at larger scale. Considering that FO, and especially UFO-MBR, technologies are newer and have much room for improvement, it is not difficult to envision that the UFO-MBR may eventually be a competitive potable reuse technology.

\section{Acknowledgments}

This study was supported by the National Science Foundation Engineering Research Center Program under Cooperative Agreement EEC-1028968 (ReNUWIt). The authors also thank the Orange County Water District administration and operations staff for providing facility materials quantity, energy use, and chemical use data that was integral to this research. The authors thank Hydration Technology Innovations for the membrane material data they provided and their general technical support on membrane cassette design. Finally, the authors thank Dr. Mengistu Geza at the Colorado School of Mines and to Dr. Bryan Coday at Carollo Engineers for the development of the FOROSA software.

\section{References}

[1] NRC, Water reuse : potential for expanding the nation's water supply through reuse of municipal wastewater, National Academies Press, Washington, D.C., 2012, 978-0-30925749-7.

[2] H.L. Leverenz, G. Tchobanoglous, T. Asano, Direct potable reuse: a future imperative, J. Water Reuse. Desal. 1 (2011) 2-10. 
[3] Y. Zang, Y. Li, C. Wang, W. Zhang, W. Xiong, Towards more accurate life cycle assessment of biological wastewater treatment plants: a review, J. Clean Prod. 107 (2015) 676-692.

[4] J.R. Stokes, A. Horvath, Energy and air emission effects of water supply, Environ. Sci. Technol. 43 (2009) 2680-2687.

[5] F. Vince, E. Aoustin, P. Breant, F. Marechal, LCA tool for the environmental evaluation of potable water production, Desalination 220 (2008) 37-56.

[6] M. Ortiz, R.G. Raluy, L. Serra, J. Uche, Life cycle assessment of water treatment technologies: wastewater and water-reuse in a small town, Desalination 204 (2007) 121131.

[7] ISO, Standard 14040 - Environmental management - Life cycle assessment - Principles and framework (2006) Ganeva, International Organization of Standardization.

[8] ISO, Standard 14044 - Environmental management - Life cycle assessment Requirements and guidelines (2006) Ganeva, International Organization of Standardization.

[9] P.P. Kalbar, S. Karmakar, S.R. Asolekar, Assessment of wastewater treatment technologies: life cycle approach, Water Environ. J. 27 (2013) 261-268.

[10] J. Foley, D. de Haas, K. Hartley, P. Lant, Comprehensive life cycle inventories of alternative wastewater treatment systems, Water Res. 44 (2010) 1654-1666.

[11] B.D. Coday, N. Almaraz, T.Y. Cath, Forward osmosis desalination of oil and gas wastewater: Impacts of membrane selection and operating conditions on process performance, J. Membr. Sci. 488 (2015) 40-55.

[12] N.T. Hancock, N. Black, T.Y. Cath, Life cycle assessment of hybrid osmotically driven membrane processes for seawater desalination and wastewater reclamation, Water Res. 46 (2012) 1145-1154.

[13] A. Fenu, J. Roels, T. Wambecq, K. De Gussem, C. Thoeye, G. De Gueldre, B. Van De Steene, Energy audit of a full scale MBR system, Desalination 262 (2010) 121-128.

[14] J. Arevalo, G. Garralon, F. Plaza, B. Moreno, J. Perez, M.A. Gomez, Wastewater reuse after treatment by tertiary ultrafiltration and a membrane bioreactor (MBR): A comparative study, Desalination 243 (2009) 32-41.

[15] Water plan update 2005, 2005, California Department of Water Resources, http://www.waterplan.water.ca.gov 
[16] S.A. Snyder, S. Adham, A.M. Redding, F.S. Cannon, J. DeCarolis, J. Oppenheimer, E.C. Wert, Y. Yoon, Role of membranes and activated carbon in the removal of endocrine disruptors and pharmaceuticals, Desalination 202 (2007) 156-181.

[17] W.A. Phillip, J.S. Yong, M. Elimelech, Reverse draw solute permeation in forward osmosis: Modeling and experiments, Environ. Sci. Technol. 44 (2010) 5170-5176.

[18] D. Fatta-Kassinos, M.I. Vasquez, K. Kummerer, Transformation products of pharmaceuticals in surface waters and wastewater formed during photolysis and advanced oxidation processes - Degradation, elucidation of byproducts and assessment of their biological potency, Chemosphere 85 (2011) 693-709.

[19] C. Yang, Y.R. Xu, K.C. Teo, N.K. Goh, L.S. Chia, R.J. Xie, Destruction of organic pollutants in reusable wastewater using advanced oxidation technology, Chemosphere 59 (2005) 441-445.

[20] A. Achilli, T.Y. Cath, E.A. Marchand, A.E. Childress, The forward osmosis membrane bioreactor: A low fouling alternative to MBR processes, Desalination 239 (2009) 10-21.

[21] A. Alturki, J. McDonald, S.J. Khan, F.I. Hai, W.E. Price, L.D. Nghiem, Performance of a novel osmotic membrane bioreactor (OMBR) system: flux stability and removal of trace organics, Bioresour Technol. 113 (2012) 201-206.

[22] E.R. Cornelissen, D. Harmsen, K.F. de Korte, C.J. Ruiken, J.J. Qin, H. Oo, L.P. Wessels, Membrane fouling and process performance of forward osmosis membranes on activated sludge, J. Membr. Sci. 319 (2008) 158-168.

[23] R.W. Holloway, J. Regnery, L.D. Nghiem, T.Y. Cath, Removal of trace organic chemicals and performance of a novel hybrid ultrafiltration-osmotic membrane bioreactor, Environ. Sci. Technol. 48 (2014) 10859-10868.

[24] R.W. Holloway, A.S. Wait, A. Fernandes da Silva, J. Herron, M.D. Schutter, K. Lampi, T.Y. Cath, Long-term pilot scale investigation of novel hybrid ultrafiltration-osmotic membrane bioreactors, Desalination 363 (2015) 64-74.

[25] W. Luo, F.I. Hai, W.E. Price, L.D. Nghiem, Water extraction from mixed liquor of an aerobic bioreactor by forward osmosis: Membrane fouling and biomass characteristics assessment, Sep. Purif. Technol. 145 (2015) 56-62.

[26] J.-M. Tan, G. Qiu, Y.-P. Ting, Osmotic membrane bioreactor (OMBR) for municipal wastewater treatment and the effects of silver nanoparticles on system performance, J. Clean Prod. 88 (2014) 146-151.

[27] X.H. Wang, B. Yuan, Y. Chen, X.F. Li, Y.P. Ren, Integration of micro-filtration into osmotic membrane bioreactors to prevent salinity build-up, Bioresour Technol. 167 (2014) 116-123. 
[28] J.S. Zhang, W.L.C. Loong, S.R. Chou, C.Y. Tang, R. Wang, A.G. Fane, Membrane biofouling and scaling in forward osmosis membrane bioreactor, J. Membr. Sci. 403 (2012) 8-14.

[29] W.C.L. Lay, Q.Y. Zhang, J.S. Zhang, D. McDougald, C.Y. Tang, R. Wang, Y. Liu, A.G. Fane, Study of integration of forward osmosis and biological process: Membrane performance under elevated salt environment, Desalination 283 (2011) 123-130.

[30] G. Qiu, Y.-P. Ting, Direct phosphorus recovery from municipal wastewater via osmotic membrane bioreactor (OMBR) for wastewater treatment, Bioresour Technol. 170 (2014) 221-229.

[31] G. Qiu, Y.-P. Ting, Short-term fouling propensity and flux behavior in an osmotic membrane bioreactor for wastewater treatment, Desalination 332 (2014) 91-99.

[32] X. Wang, Y. Chen, B. Yuan, X. Li, Y. Ren, Impacts of sludge retention time on sludge characteristics and membrane fouling in a submerged osmotic membrane bioreactor, Bioresour Technol. 161 (2014) 340-347.

[33] A.A. Alturki, J.A. McDonald, S.J. Khan, W.E. Price, L.D. Nghiem, M. Elimelech, Removal of trace organic contaminants by the forward osmosis process, Sep. Purif. Technol. 103 (2013) 258-266.

[34] T.Y. Cath, N.T. Hancock, C.D. Lundin, C. Hoppe-Jones, J.E. Drewes, A multi-barrier osmotic dilution process for simultaneous desalination and purification of impaired water, J. Membr. Sci. 362 (2010) 417-426.

[35] A. D'Haese, P. Le-Clech, S. Van Nevel, K. Verbeken, E.R. Cornelissen, S.J. Khan, A.R.D. Verliefde, Trace organic solutes in closed-loop forward osmosis applications: Influence of membrane fouling and modeling of solute build-up, Water Res. 47 (2013) $5232-5244$.

[36] N.T. Hancock, P. Xu, D.M. Heil, C. Bellona, T.Y. Cath, Comprehensive bench- and pilot-scale investigation of trace organic compounds rejection by forward osmosis, Environ. Sci. Technol. 45 (2011) 8483-8490.

[37] R.V. Linares, V. Yangali-Quintanilla, Z.Y. Li, G. Amy, Rejection of micropollutants by clean and fouled forward osmosis membrane, Water Res. 45 (2011) 6737-6744.

[38] M. Xie, L.D. Nghiem, W.E. Price, M. Elimelech, Comparison of the removal of hydrophobic trace organic contaminants by forward osmosis and reverse osmosis, Water Res. 46 (2012) 2683-2692. 
[39] N.T. Hancock, P. Xu, M.J. Roby, J.D. Gomez, T.Y. Cath, Towards direct potable reuse with forward osmosis: Technical assessment of long-term process performance at the pilot scale, J. Membr. Sci. 445 (2013) 34-46.

[40] K.Y. Wang, M.M. Teoh, A. Nugroho, T.-S. Chung, Integrated forward osmosismembrane distillation (FO-MD) hybrid system for the concentration of protein solutions, Chem. Eng. Sci. 66 (2011) 2421-2430.

[41] K.C. Wijekoon, F.I. Hai, J.G. Kang, W.E. Price, W.S. Guo, H.H. Ngo, T.Y. Cath, L.D. Nghiem, A novel membrane distillation-thermophilic bioreactor system: Biological stability and trace organic compound removal, Bioresour Technol. 159 (2014) 334-341.

[42] M. Niero, M. Pizzol, H.G. Bruun, M. Thomsen, Comparative life cycle assessment of wastewater treatment in Denmark including sensitivity and uncertainty analysis, J. Clean Prod. 68 (2014) 25-35.

[43] W.W. Mo, Q. Zhang, Energy-nutrients-water nexus: Integrated resource recovery in municipal wastewater treatment plants, J. Environ. Manag. 127 (2013) 255-267.

[44] R.S. Hilaire, M.A. Arnold, D.C. Wilkerson, D.A. Devitt, B.H. Hurd, B.J. Lesikar, V.I. Lohr, C.A. Martin, G.V. McDonald, R.L. Morris, D.R. Pittenger, D.A. Shaw, D.F. Zoldoske, Efficient water use in residential urban landscapes, Hortscience 43 (2008) 2081-2092.

[45] M.A. Harivandi, Evaluating recycled waters for golf course irrigation, Green Section Record (2004)

[46] D.Y. Kim, B. Gu, J.H. Kim, D.R. Yang, Theoretical analysis of a seawater desalination process integrating forward osmosis, crystallization, and reverse osmosis, J. Membr. Sci. 444 (2013) 440-448.

[47] S. Sethi, S. Walker, J. Drewes, P. Xu, Existing \& emerging concentrate minimization \& disposal practices for membrane systems, Florida Water Resourc. J. 58 (2006) 38-48.

[48] S. Judd, The MBR book: Principles and applications of membrane bioreactors for water and wastewater treatment, 2nd edition, Elsevier, 2011, 978-0-08-096682-3.

[49] WESTWeb, 2015, west.berkeley.edu/model.php

[50] J.R. Stokes, A. Horvath, Life cycle energy assessment of alternative water supply systems, Int. J. Life Cycle Ass. 11 (2006) 335-343.

[51] L. Miller-Robbie, B.A. Ulrich, D.F. Ramey, K.S. Spencer, S.P. Herzog, T.Y. Cath, J.R. Stokes, C.P. Higgins, Life cycle energy and greenhouse gas assessment of the coproduction of biosolids and biochar for land application, J. Clean. Produc. 91 (2015) 118127. 
[52] J.R. Stokes, A. Horvath, Supply-chain environmental effects of wastewater utilities, Environ. Res. Lett. 5 (2010) 014015.

[53] J.R. Stokes, A. Horvath, R. Sturm, Water Loss Control Using Pressure Management: Life-cycle Energy and Air Emission Effects, Environ. Sci. Technol. 47 (2013) 1077110780.

[54] A. Shehabi, J.R. Stokes, A. Horvath, Energy and air emission implications of a decentralized wastewater system, Environ. Res. Lett. 7 (2012) 024007.

[55] X. Mayer, T.Y. Cath, Development of a hybrid forward osmosis-reverse osmosis design and analysis program, Colorado School of Mines, (2011).

[56] J.R. McCutcheon, M. Elimelech, Influence of concentrative and dilutive internal concentration polarization on flux behavior in forward osmosis, J. Membr. Sci. 284 (2006) 237-247.

[57] T.Y. Cath, M. Elimelech, J.R. McCutcheon, R.L. McGinnis, A. Achilli, D. Anastasio, A.R. Brady, A.E. Childress, I.V. Farr, N.T. Hancock, J. Lampi, L.D. Nghiem, M. Xie, N.Y. Yip, Standard methodology for evaluating membrane performance in osmotically driven membrane processes, Desalination 312 (2013) 31-38.

[58] Y. Yoon, P. Westerhoff, S.A. Snyder, E.C. Wert, Nanofiltration and ultrafiltration of endocrine disrupting compounds, pharmaceuticals and personal care products, J. Membr. Sci. 270 (2006) 88-100.

[59] Kubota submerged membrane unit, 2012, http://www.kubota-mbr.com/resources/Kubota Main MBR Brochure.pdf

[60] ROSA system design 2013, http://www.dowwaterandprocess.com/en/Resources/ROSA_System_Design_Software

[61] B. Appelbaum, Water and sustainability: U.S. electricity consumption for water supply and treatment-The next half century, 2002, Palo Alto, CA.

[62] Electricity use and management in the municipal water supply and wastewater industries, 2013, http://www.waterrf.org/PublicReportLibrary/4454.pdf

[63] Metcalf, I. Eddy, G. Tchobanoglous, F. Burton, H.D. Stensel, Wastewater engineering: Treatment and reuse, McGraw-Hill Companies,Incorporated, 2002, 978-0-07-041878-3.

[64] M. Lundin, M. Bengtsson, S. Molander, Life cycle assessment of wastewater systems: Influence of system boundaries and scale on calculated environmental loads, Environ. Sci. Technol. 34 (2000) 180-186. 
[65] Puron hollow fiber membrane modules, http://www.kochmembrane.com/PDFs/DataSheets/Hollow-Fiber/UF/puron-mbr-modules-psh330-660-1800-datasheet.aspx

[66] S. Allgeier, B. Alspach, J. Vickers, Membrane filtration guidance manual, 2005, US EPA, http://yosemite.epa.gov/water/owrccatalog.nsf/065ca07e299b464685256ce50075c11a/21 93b9bde71292ec852571290067cb4c!OpenDocument

[67] Texas Commission on Environmental Quality, Removal credits for reverse osmosis membranes, 2014, http://www.tceq.texas.gov/assets/public/permitting/watersupply/pdw/Removal_Credit_R O_Membranes.pdf 


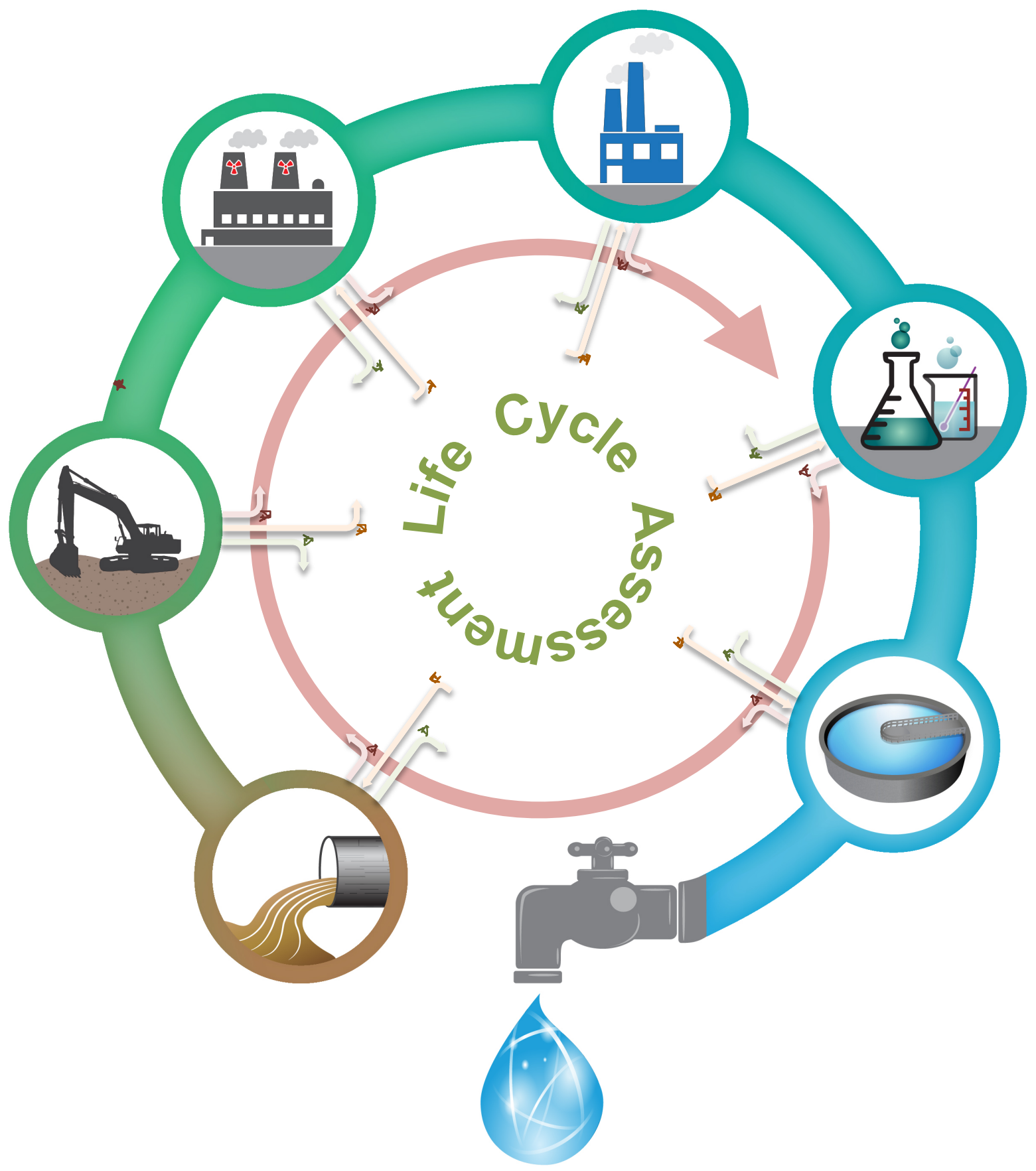

